\title{
Recent earthquake activity in Trichonis region and its tectonic significance
}

\author{
N. Delibasis $(*)-$ P. Carydis (**)
}

Received on May 10 nd, 1977

SUMmARY. - The aftershock activity associated with the central Greece (Trichonis Lake) earthquake of June-Dec. 1975, has been studied, with emphasis on the time and magnitude distribution. It has been found that the value of $b$, in Gutenberg-Richter's relationship was near the same for the primary as well as the secondary or second order aftershocks of the sequences, but depends upon the focal depth.

A correlation between the calculated focal mechanisms and the associated stress components to the distribution pattern of meizoseismic effects as well as to the geological structure of the seismic region was found.

The seismic region lies at the top of an anticline which was found moving downwards, apparently due to compressional stresses.

Within the series of three earthquakes the progress of the destruction of the buildings was observed and reported. The interest is concentrated to modern buildings out of reinforced concrete and infill brick walls. The relatively unexpected rather bad performance of the later case of buildings was compared to that of the traditional small houses out of brick or stone masonry, the behaviour of which may be considered as better from what it was expected.

Riassunto. - Viene studiata l'attività delle repliche associate al terremoto avvenuto nel periodo giugno-dicembre 1975 nella Grecia centrale (Lago Trichonis), con particolare riguardo alla distribuzione e nel tempo e della magnitudo. Si è trovato che il valore di $b$, nella relazione Gutenberg-Richter, è stato pressoché lo stesso nelle serie di repliche primarie e secondarie, o di secondo ordine, ma dipende dalla profondità ipocentrale. E stata quindi evidenziata una correlazione tra $\mathrm{i}$ meccanismi focali calcolati e le componenti di

$\left({ }^{*}\right)$ Seismological Institute, National Observatory of Athens, Greece.

$\left.{ }^{* *}\right)$ Institute of Structural Analysis and Aseismic Research, National Technical University of Athens, Greece. 
stress associate al modello di distribuzione degli effetti mesosismici, come pure alla struttura geologica della regione sismica.

La regione sismica è situata alla cima di un'anticlinale che tende a slittare verso il basso, apparentemente a causa di tensioni compressionali.

La progressiva distruzione degli edifici è stata osservata e descritta nell'arco delle serie di tre terremoti. L'interesse è concentrato sulle moderne costruzioni in cemento armato e mattoni pieni. Il comportamento, relativamente inatteso ed alquanto deludente, degli edifici di quest'ultimo tipo è stato paragonato a quello delle tradizionali piccole case realizzate in pietre o mattoni, ed il cui comportamento può essere considerato migliore di quanto ci si attendesse.

\section{INTRODUCTION.}

During the period June-December 1975 a series of three strong earthquakes occurred near the northern coast of the Gulf of Patras, in the lower reaches of the Evinos River, where the bed seems to be predetermined by a fracture zone.

The first earthquake of magnitude $M_{s}=5.4$, occurred at $13 \mathrm{~h} 26 \mathrm{~m}$ and $55 \mathrm{~s}$ G. M. T. of June 30, 1975 was located at $38^{\circ} 29^{\prime} 18^{\prime \prime} \mathrm{N}, 21^{\circ} 40^{\prime}$ $00^{\prime \prime} E$ with a shallow focus at a depth of about $10 \mathrm{~km}, 3 \mathrm{~km}$ east of the Kato-Makrynou village, where the maximum cumulative M. M. intensity reached VII to VIII degrees. According to official reports the shock produced properiy damage to several localities. 60 old houses where damaged beyond repair and 34 cracked.

The second earthquake of magnitude $M_{\mathrm{s}}=53 / 4$, occurred at $16 \mathrm{~h}$ $07 \mathrm{~m} 51.7 \mathrm{~s}$ G.M. T. of December 21, 1975; its epicenter was calculated at $38^{\circ} 29^{\prime} 17^{\prime \prime} \mathrm{N}, 21^{\circ} 45^{\prime} 05^{\prime \prime} E$ with a depth of $0 \mathrm{~km}, 11 \mathrm{~km}$ east of the Kato-Makrynou village, where it was impossible to estimate the maximum intensity, because the third strong earthquake of the series occurred 10 days later.

The third earthquake of magnitude $M_{s}=5.9$, occurred at $09 \mathrm{~h} 46 \mathrm{~m}$ $9.5 s$ G. M. T. of December 31, 1975; its epicenter wass located at $38^{\circ}$ $30^{\prime} 8^{\prime \prime} \mathrm{N}, 21^{\circ} 46^{\prime} 07^{\prime \prime} \mathrm{E}$ with a depth of $3 \mathrm{~km}, 12 \mathrm{~km}$ east of the KatoMarkrynou village. The observed maximum cumulative $M$. M. intensity was VIII to IX degrees at Kato-Makrynou. A few cases of landslides and ground cracks were observed in the epicentral tract. According to official reports, 200 old houses were destroyed and 580 were seriously cracked. One person died and two slightly injured on account of the larger shock. 
The first and third shocks were preceded and followed by a significant foreshock and aftershock activity, where more than 2000 aftershocks were registered with magnitude $M_{L}$ between 1.5 and 4.6.

The series of the three strong earthquakes with the numerous aftershocks caused an extensive property damage at several localities, particularly in the southeastern part of the Trichonis lake, as well as panic and anxiety to the people for the possibility of future tremors.

The authors visited the meizoseismal area (extended over $140 \mathrm{sq} . \mathrm{km}$ ) immediately after the first and third earthquakes.

In the present paper a correlation between the calculated focal mechanisms and the associated stress components to the distribution pattern of the macroseismic effects and the geological structure of the seismic region is attempted.

By statistical analysis of the seismic sequences under investigation, a rational expression of the nature of aftershocks is attempted in order to determine their characteristics.

\section{SEISMICITY OF THE AREA.}

At the folded regions of the Western Greece the most earthquake destructions are associated with dislocations of the Ionian zone. Among these dislocations is the Agrinio-Arta fault zone.

The western part of Central Greece to which belongs the affected region, tectenically is one of the active areas of Greece. Small earthquakes occurred within this region, and some were felt at Trichonis area. Ten earthquakes were shallow with a magnitude of $43 / 4-5.9$.

During the period 1880 and 1970, the most significant earthquakes are the following:

1882, Aug. 31: Strong earthquake notion $\left(38 \frac{1}{2}{ }^{0} N, 235 / 4^{0} E\right)$, which caused slight damages at the town of Agrinion. The maximum M. M. intensity was VI degree.

1885, Feb. 18: Strong earthquake $\left(381 / 2^{0} N, 213 / 4^{0} E\right)$, which caused damages of VII degree of the M. M. scale in the vicinity of the town of Naupaktos.

1907, Nov. 7: Strong earthquake motion $\left(38^{5 / 4} \mathbf{4}^{0} \mathrm{~N}, 211^{1 / 4^{0} E}\right)$ of $M=43 / 4$, with damages of V-VI degree in the town of Amphilochia. 
1921, Sept. 13: Strong earthquake motion $\left(383 / 4^{0} N, 211 / 4^{0} E\right)$ of $M=53 / 4$ caused V-VI degree damages in the region of Amphilochia. The shock was followed by a number of aftershocks, the strongest of which had a magnitude $M=5.1$.

1949, Oct. 4: Strong earthquake in Aetolia $\left(38.5^{\circ} \mathrm{N}, 21.8^{\circ} \mathrm{E}\right)$, of $M=5.1$, caused significant damages in the village of Thermon. The shock was preceded by slight foreshocks, and followed by numerous aftershocks one of which had a magnitude $M=51 / 4$.

1953, Dec. 21: Strong earthquake of $M=5.2$. The shock occurred $13 \mathrm{~h} 20 \mathrm{~m} 58 \mathrm{~s}$, was located at the south part of the Trichonis lake $\left(38.5^{\circ} \mathrm{N}, 21.1^{\circ} \mathrm{E}\right)$. Damages of VIII degree were observed at Messarista.

1955, Dec. 21: Strong earthquake of $M=51 / 4$. The shock occurred at $21 \mathrm{~h} 40 \mathrm{~m} 24 \mathrm{~s}\left(38.6^{\circ} \mathrm{N}, 21.4^{\mathrm{C}} \mathrm{E}\right)$, near the $N W$ coast of the Trichonis lake.

1960, May 5: Stronge earthquake of $M=43 / 4-5$. The shock occurred

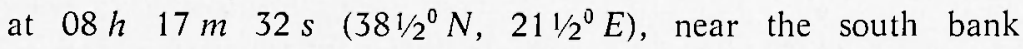
of Trichonis lake, caused damages of V-VII degree at the villages of Paravola, Mataraga and Grammatikon.

Until 1966 the seismic activity of the region of Aetoloakarnania did not exceed the 53/4 magnitude level. An increase of the earthquake activity was observed immediately after the impounding of the artificial lake of Kremasta, in 1966.

Macroseismic data from the beginning of the nineteenth century up to 1970 show a maximum M. M. intensity of VII - VIII degrees. P. Comninakis 1975 using seismic data from 1911 up to 1970 found by statistical analysis, that the maximum earthquake magnitude with the greatest probability of occurrence once per year per $1 / 4$ degree in the area of Trichonis lake is 3.6.

\section{Regional geologic setting.}

The affected area is situated in the western flanc of Hellenides and belongs to the external isopic zones of Pindus, Gavrovo and partly to the Ionian zone. The zones follow the general trend of mountain ranges of the Dinarotauric arc of S-E Europe (NNW-SSE), see Fig. 1. 


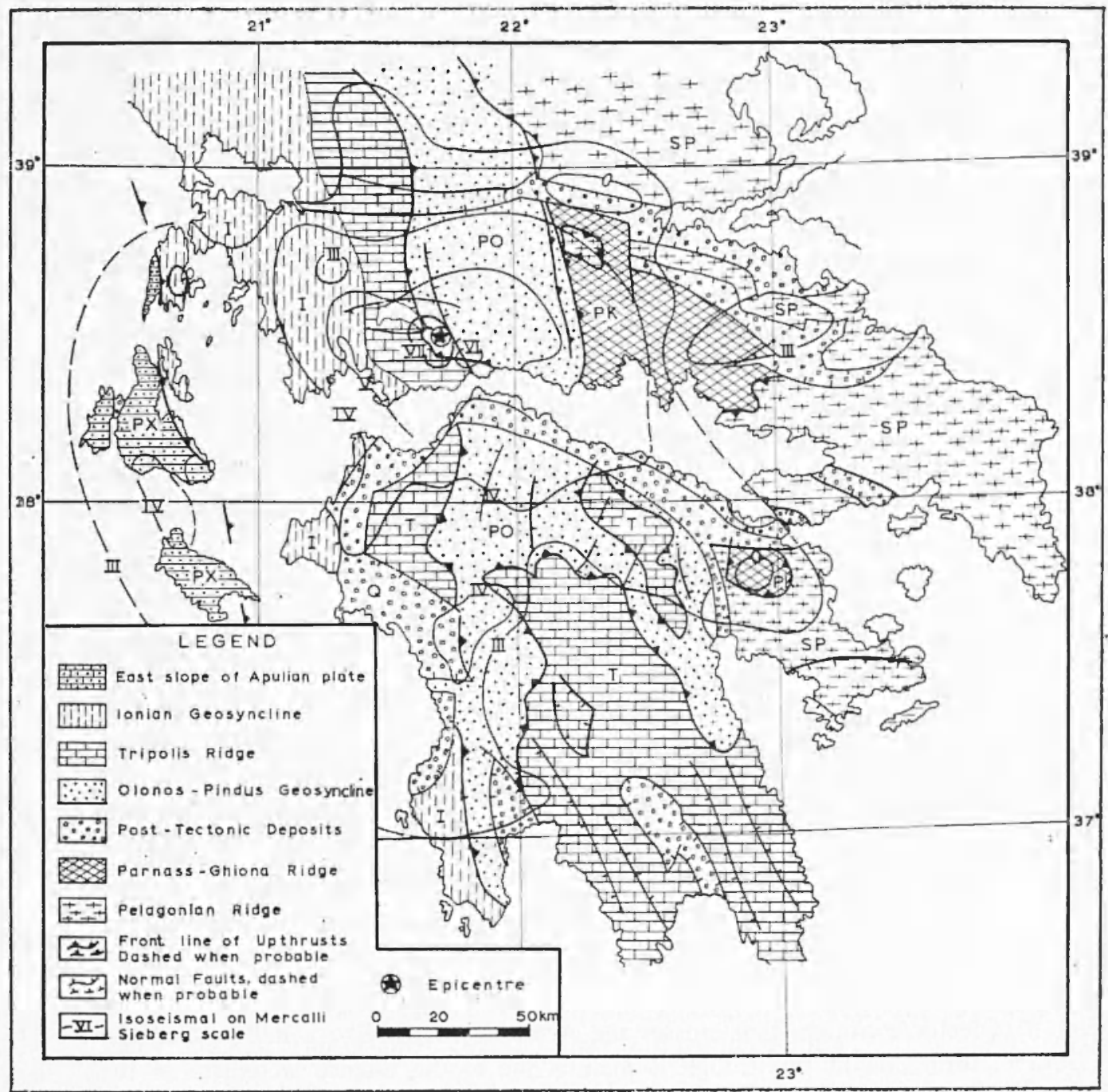

Fig. 1. The Seismotectonic map of Central Greece. Tectonic zones after J. Bornovas et al, 1971; Isoseismal lines for the earthquake of June 30, 1975. 
The Pindus Zone is formed from Pelagic sediments overthrusting the neighbouring zone of Gavrovo.

Jurassic and Cretaceous carbonates are common in the Pindus thrust zone, where ophiolithes appear with shales and radiolarian cherts, then flysch deposits overthrusted them.

In this zone the plastic tectonic formation of foldings dominates as are the overthrusts and tectonic nappes.

The Gavrovo-Tripolitsa Zone is formed out of neritic sedimental deposits which have been overlaid the meiogeoanticline ridge.

The age of these sedimental deposits belongs to the Cretaceous, Mid-Eocene period. On the top of the above mentioned sediments lays flysch belonging to the Upper Eocene and Oligocene. The tectonic of this zone is characterized by a sequence of anticlines and synclines with many faults and strong displacements.

The Ionian Zone consists out of sediments belonging to the Pelagic phase, while weak overthrusts directed westwards characterize the tectonic of the zone.

The westwards strong movement thrusts have been developed during the Pindus orogenesis (Miocene), and divide the region into a sequence of tectonic nappes with a predominant direction NNW-SSE. The whole region presents intense tectonic formation with parallel and perpendicular multiple faultings to the direction of the Pindus zone.

The region is located between anticlines and has been affected by numerous faults: two of the most significant are the following:

a) The Evinos fault which almost follows the homonymous valley with $N E-S W$ direction and right-lateral motion.

b) The dip-slip displacements observed in the eastern side of Trichonis lake.

The lake of Trichonis occupies the east edge of the fractured tectonic trough, that crosses the Aetoloakarnania like a half circle. The formation of this trough is mainly due to the intense tectonism of the area under consideration and partly to the falling down of limestone masses into the existing underground caverns, which form a quite extensive underground Carstic network. The above mentioned limestones belong to the Cretaceous and Jurassic period. The underground caverns of this network are being enlarged due to the corrosive and solvent action of the water, resulting thus to the fall of the overlying layers and, finally, to the change of the morphology of the region. 


\section{Statistical study of aftershock sequence.}

\section{Histogram and frequency distribution.}

At first it was attempted to prove statistically that the events were not random or did not belong to some microearthquake swarm but to an aftershock sequence. A comparison was made between the Poisson distribution and the plot showing the percentage of hour intervals in which a certain number of earthquakes occurred versus the number of shocks per hour. Similar work has been done by Knopoff 1964 for the earthquakes of southern California and Drakopoulus 1970 in the study of Epidauros sequence.

In order to find the Poisson distribution, the following expression was used:

$$
Z_{n} \simeq \bar{n} \frac{n}{n !}
$$

where $n$ is the number of events per hour $Z n$ denotes the number of samples (where $n$ events are observed) and $n$ the average number of events per hour.

The plot of $Z n$ derived from eq. (1) for the first aftershock sequence is shown in Fig. 2, as well as the normal Poisson Distribution. From this figure one can easily see that there is no coincidence between the $Z n$ histogram with the law of Poisson's distribution. That means that the observed sequence is not random, but it is a dependent one and in our case is an aftershock sequence.

\section{Temporal Distribution of Aftershocks.}

The distribution of aftershocks in time has often been studied by many authors. The original Omori's law was modified into

$$
n(t) \mathrm{d} t=K(t+c)^{-h} \mathrm{~d} t
$$

where $t$ is the time after the main shock, $n(t) \mathrm{d} t$ is the number of aftershocks occurring in the time interval $t$ and $t+\mathrm{d} t$ and $K, c$ and $h$ are constants chosen to fit the data.

when $h=1$, eq. (2) expresses the Omori's law. 


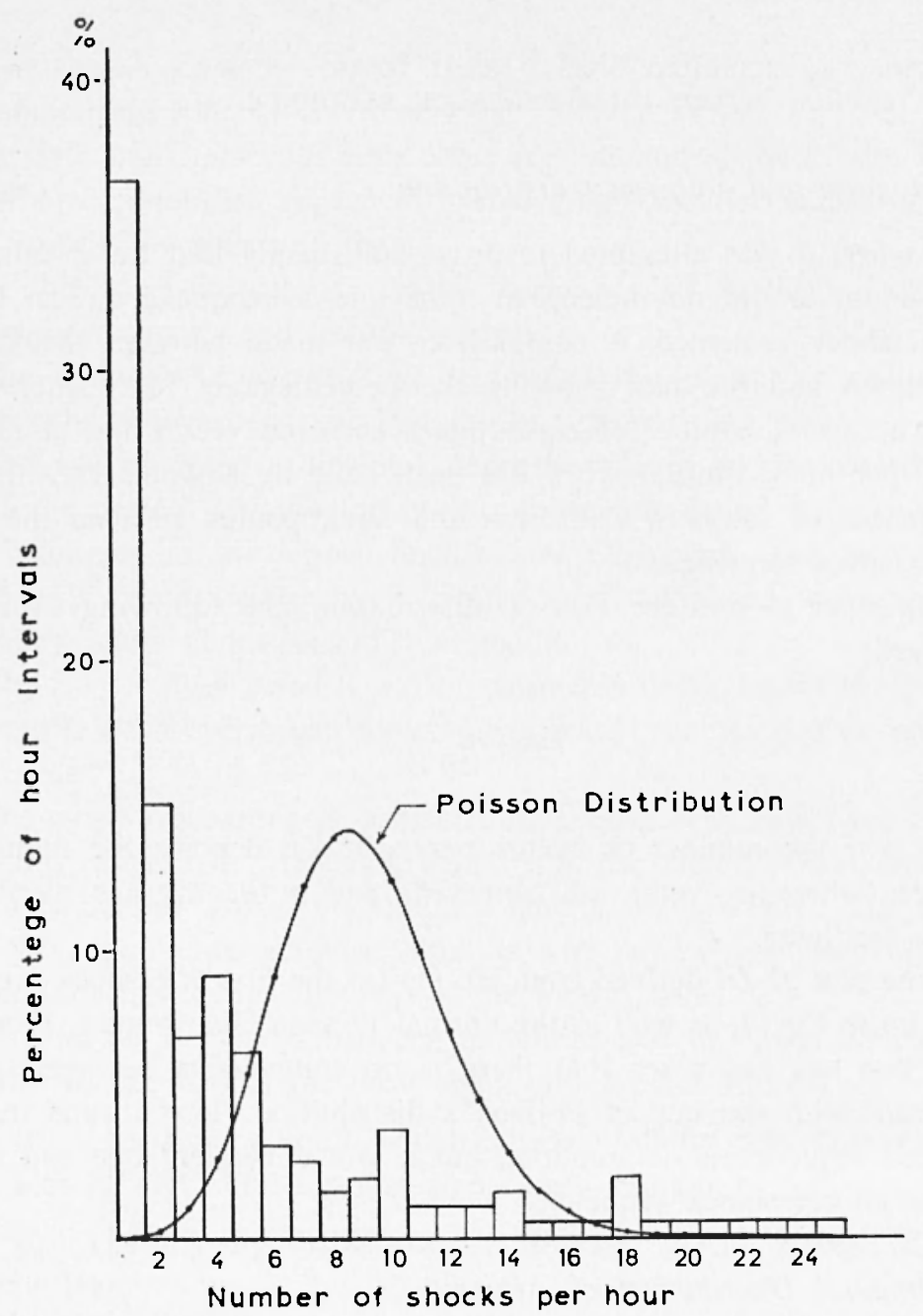

Fig. 2. Number of shocks per hour vs percentage of hour for the first series.

Drakopoulos 1968 determined the cumulative frequency of many earthquakes in Greece using the relation:

$$
N(t)=\int_{i}^{t_{0}} \cdot n_{i}(t) \mathrm{d} t
$$

By applying eq. [3] it was found that the functions that best fit the data are of the following type.

$$
N=N_{i} t^{-H} \text { for } t<t_{0}
$$


where $t_{0}$ is the time which the decay of the number of aftershocks is more abrupt.

$$
\log N=B-H \log t
$$

The constant $H$ may depend on the viscosity of the medium.

The logarithm of the number $N$ of aftershocks which occurred $t-1$ days after the main shock of June 30, 1975 versus the logarithm of $t$, is plotted in Fig. 3. This plot is composed of two straight lines with the constants of eq. 5 given as follows:

$$
\begin{aligned}
& \log N=2.986-0.954 \log t \\
& \log N=18.46-12.37 \log t
\end{aligned}
$$

The frequency distribution for the second aftershock sequence of the series within the time interval of 21 to 31 December 1975 is plotted in Fig. $4 a$, with the frequency law:

$$
\log N=2.74-1.14 \log t \text {. }
$$

The distribution of the third aftershock sequence, for the period of time from 31 December 1975 to 30 January 1976, is plotted in Fig. $4 b$;

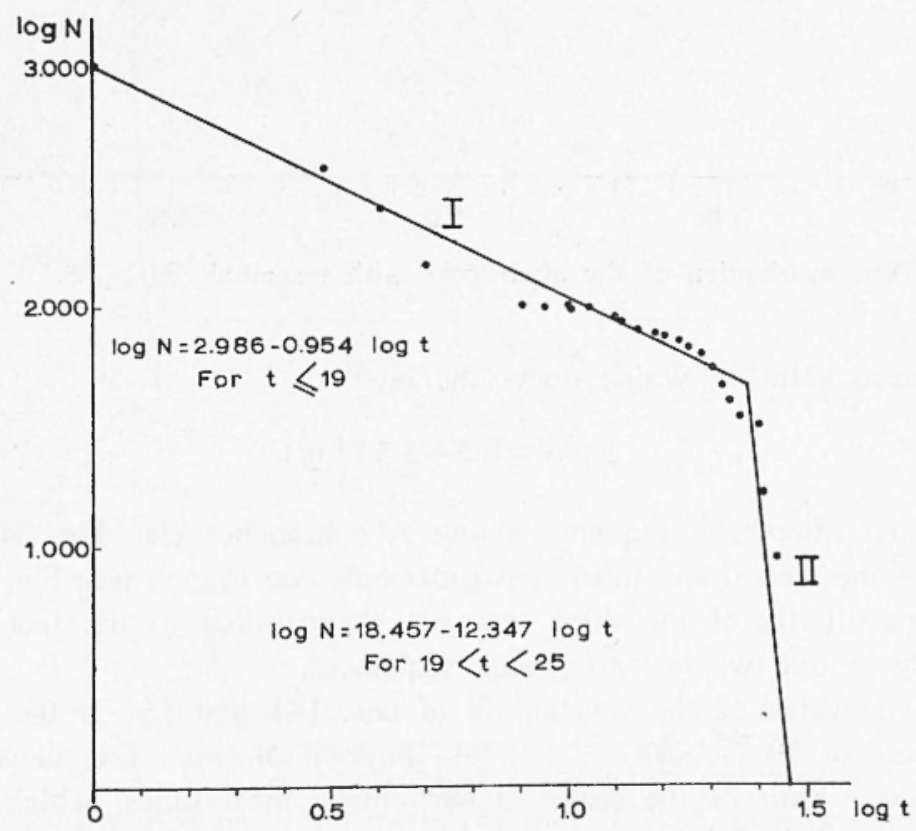

Fig. 3. Time distribution of the aftershocks with magnitude $M_{L} \geq 1.5$. 


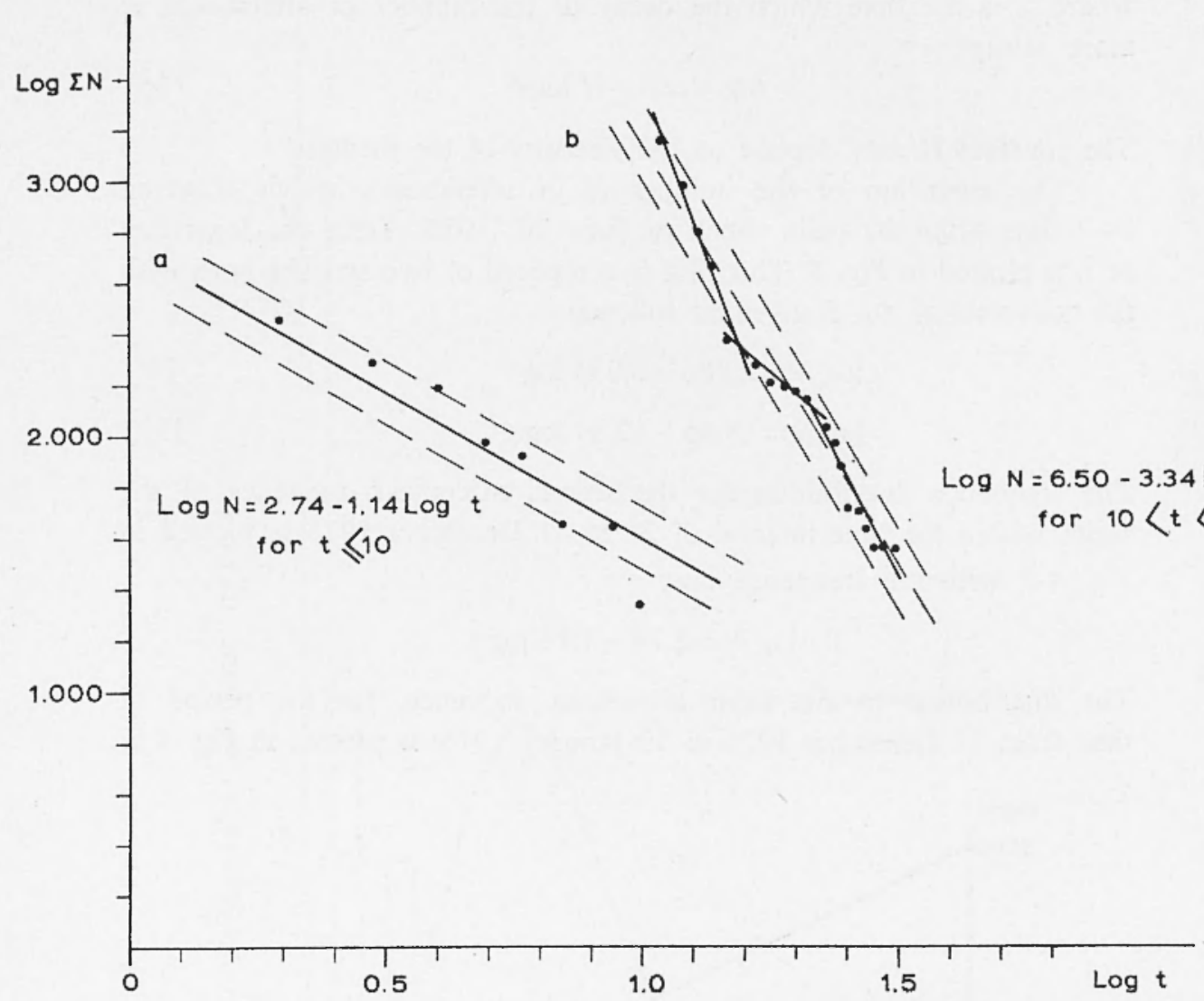

Fig. 4. Time distribution of the aftershocks with magnitude $M_{L} \geq 1.5$.

the mean value of which obeys the law:

$$
\log N=6.5-3.34 \log t
$$

The first aftershock sequence shows two branches (see Fig. 3), while that of the second and third ones show only one branch (see Fig. $4 a, b$ ). The peculiarity of the third sequence is atributed to the fact of the mixing of the two last aftershock sequences.

The value of the constant $H$ of eqs. [4] and [5] is the rate of decrease of aftershocks in a certain interval of time; this depends on the lower limit of the observed earthquake magnitudes, which in the present case is 1.5 . 
The aftershock activity started dying out, but on July 25, 1975 and January 21,1976 , two aftershocks of magnitude $M_{L}=4.6$ and $M_{L}=3.9$ occurred, respectively. These are the largest aftershocks which have been followed by their own second order aftershock sequences shown in Figs 5 and 6 respectively, where as shown, their time distribution is of the exponential type.

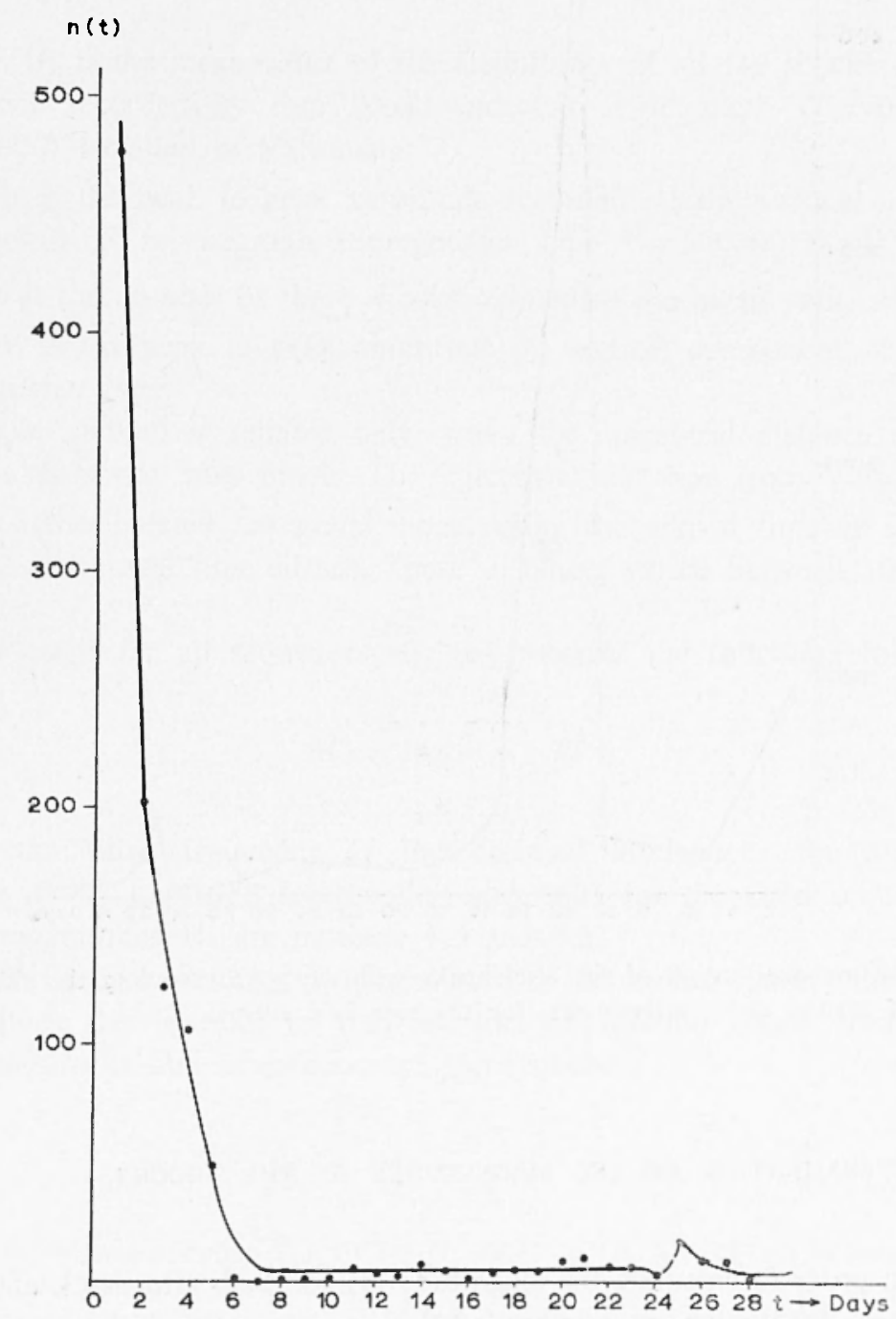

Fig. 5. Time distribution of the aftershocks with $M_{\mathrm{L}} \geq 1.5$, showing the existence of second order aftershocks, for the first event. 


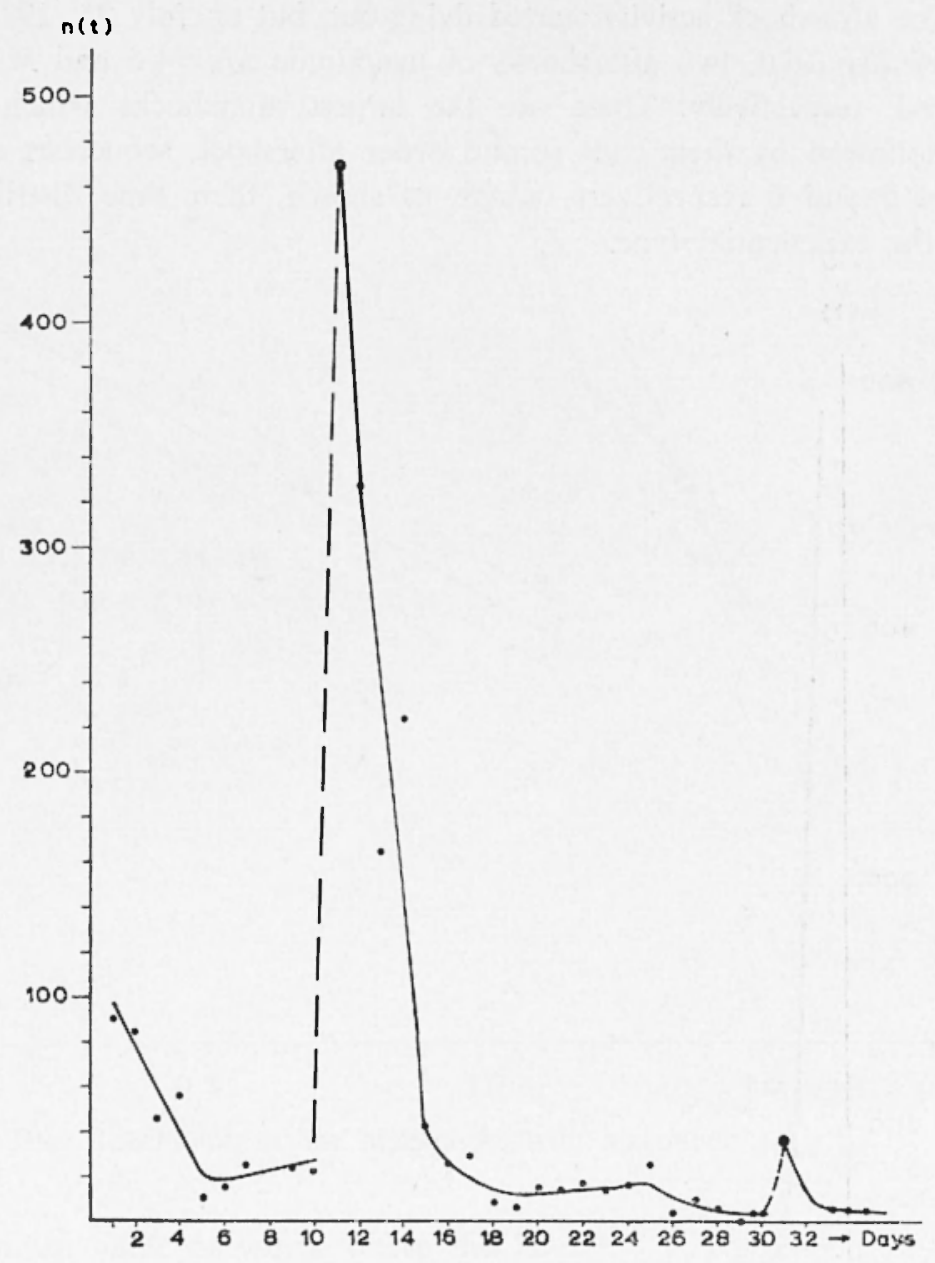

Fig. 6. Time distribution of the aftershocks with $M_{I} \geq 1.5$, showing the existence of second order aftershocks, for the two late events.

5. Determination of the Magnitudes of THE ShOCKS.

In order to calculate the magnitude $M_{L}$ for each aftershock of every sequence, for which an amplitude $A^{\prime}$ was measured at the station of 
Valsamata (VLS) (') the following relation was used:

$$
M^{\prime}{ }_{L}=\log A^{\prime}+\bar{M}_{i}-\frac{\sum_{i=1}^{n} \log A_{i}}{n}
$$

where $\overline{M_{L}}$ is the mean value of the magnitudes of all the shocks of the sequence recorded by thte Wood-Anderson seismograph $\left(T_{0}=0.8 \mathrm{sec}\right.$, $V=2800$ ) installed at Valsamata.

$A_{i}$ is the peak to peak amplitude recorded on the vertical component of $V L S$ seismograph (Spregnether type $V=50000, T_{0}=0.5 \mathrm{sec}$ ).

$n$ is the number of these shocks, related to the mean value $\bar{M}_{L}$ and

$A^{\prime}$ is the peak to peak amplitude on vertical component of $V L S$, Srengnether type.

The method is reliable only, when the epicentral distance of the shocks does not vary much. The epicentral distance from Valsamatat station is calculated for every shock, using the arrival time of several phases and travel time curves. These distances varied between 100 and $115 \mathrm{~km}$.

Finally, for all sequences eq. [6] receives the following form:

$$
M_{L}^{\prime}=\log A^{\prime}+1.73
$$

The cumulative frequency of the detected aftershocks for different values of $M_{L}$ are 1088 for the first and 1823 for the third sequences; their magnitudes $M_{L}$ are between 1.5 and 4.6.

These observations have been used to determine spatial, time and magnitude distribution, as well as, the deformation characteristics of the foreshocks and aftershocks of the sequences.

(1) Valsamata station $\left(38^{\circ} 10^{\prime} 38^{\prime \prime} N, 20^{\circ} 35^{\prime} 23^{\prime \prime} E, h=375 \mathrm{~m}\right)$ is located on Cephalonia Island. 
6. Frequency versus magnitude of the afteshocks.

Earthquakes are usually distributed according to Gutenberg-Richter 1956 relationship:

$$
\log n(M) \mathrm{d} M=(a-b M) \mathrm{d} M
$$

where $a$ and $b$ are constants $n(M) \mathrm{d} M$ is the number of earthquakes with magnitudes within the range of $M$ and $M+\mathrm{d} M$ for a specified time interval and area.

The relationship of eq. [8] was proved to be adequate for aftershock sequences.

Many investigators use instead of eq. [8], the cumulative frequency function expressed by:

$$
\log N=a-b M
$$

Page 1972 and many other investigators have shown that the constant $b$ may vary slightly depending on the physical properties of the material and the distribution of stress within the seismic region, Mogi 1963 and Minakami 1960 have found that $b$ could be much higher in volcanic shocks.

Values of $b$ have been reported from about 0.5 up to 1.5; after Isacks and Oliver $1964 b$ is mostly varying between 0.7 and 1.0 .

Drakopoulos 1968 using many cases from the area of Greece found that the values of $b$ vary between 0.4 and 1.7. Some investigators expressed the opinion that the parameter $b$ is constant and equal to about 1.0 . However, the majority of the investigators, believe that $b$ varies from region to region and with focal depth, and its value depends on the stress conditions as well as on the heterogeneity of the earthquake volume.

The logarithm of the cumulative frequency function $N(M)$ versus magnitude $M$ of the aftershocks of Trichonis earthquakes, for the whole sequence after June 31, 1975 period, is plotted in Fig. $7 \mathrm{~A}$. For the said aftershock sequence the following equation was obtained after application of the least squares method:

$$
\log N=4.57-1.0 \mathrm{M}
$$




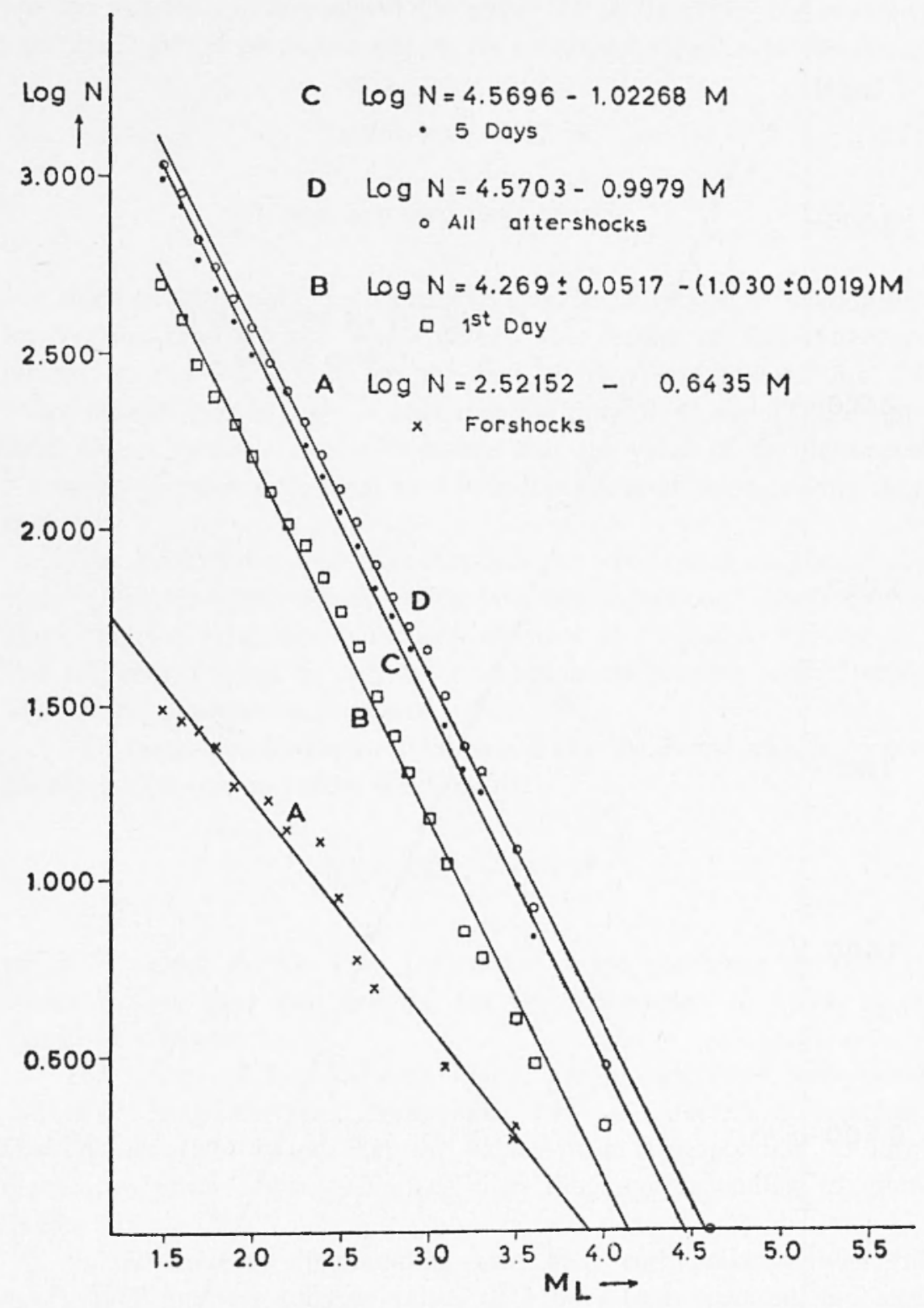

Fig. 7. Cumulative frequency distribution of magnitude for some different time intervals after the occurrence of the main shock, for the first event. 


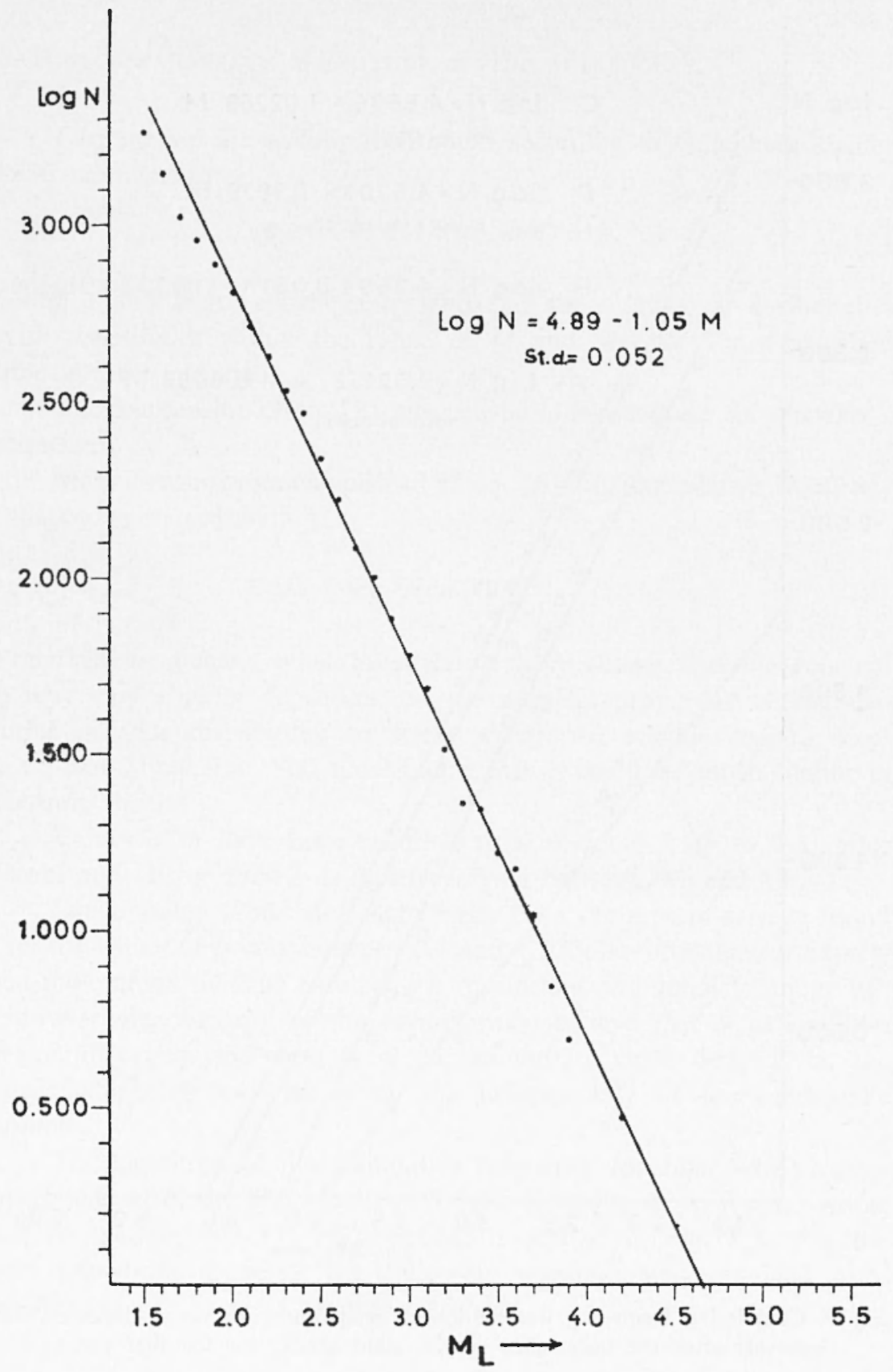

Fig. 8. Cumulative frequency function of the magnitude of aftershocks of Dec. 21 and 311975 main shocks. 
For the sequence of the period December 21 to 31,1975 the resulting function $N(M)$ is plotted in Fig. 8; its numerical values take the form:

$$
\log N=4.89-1.05 M
$$

with standard dev. $=0.052$

For the first aftershock sequence the magnitude-frequency relationship for various time periods was studied. The results of the study are plotted in Figs $>B$ and $C$ for the first 10 days and for the first 24 hours respectively. It may be seen that the plots $B, C$ and $D$ constitute three almost parallel lines. This means that the value of the parameter $b$ remains constant and equal to 1.0 , independent of the sampling time period.

The same procedure was applied for the other sequences by dividing the whole aftershock period into smaller periods. It was proved again that the parameter $b$ remains constant and equal to that of the first sequence. In Fig. 8, only the first line corresponding to the whole time of the sequence is presented.

The magnitude-frequency relationship for the foreshocks is found, for the first event, to follow the formula:

$$
\log N=2.52-0.64 M
$$

which is shown in Fig. $7 \mathrm{~A}$. The value of the parameter $b=0.64$ is obviously less than that holding for the aitershocks $(b=1.0)$, as it should be expected.

The values of $b$, previously found, are in agreement with those derived by Berg 1968 and Drakopoulos 1974, for natural earthquakes. Drakopoulos 1974 found that the values of $b$ corresponding to foreshocks are much lower $(0.3-0.6)$ than those corresponding to aftershocks $(0.75-1.2)$.

In the reservoir impounding associated earthquake activity, in Berg's 1968 analysis different values of $b$ have been reported, as listed in Table I. In all cascs the value of $b_{/ o r}$ is larger than the corresponding $b_{a f r}$. 
TABLE I

$b$ values for the reservoir impounding associated earthquake activity

\begin{tabular}{lcc} 
Region & \multicolumn{2}{c}{$b$ values } \\
& Foreshocks & Aftershocks \\
Kremasta & 1.41 & 1.12 \\
Koyna & 1.87 & 1.09 \\
Kariba & 1.18 & 1.02 \\
\hline
\end{tabular}

In the present study it was found for foreshocks the value of $b=0.64$ and for aftershocks $b=1.0$. The findings give ground to believe that the earthquake sequences of the present case has no apparent relation to reservoir impounding earthquakes as far as the parameter $b$ concerns.

Frequency-magnitude distribution curves of the last aftershock sequences are plotted for layer zones of $5 \mathrm{~km}$ thickness each in Fig. 9. Three discrete $b$-values were obtained as following:

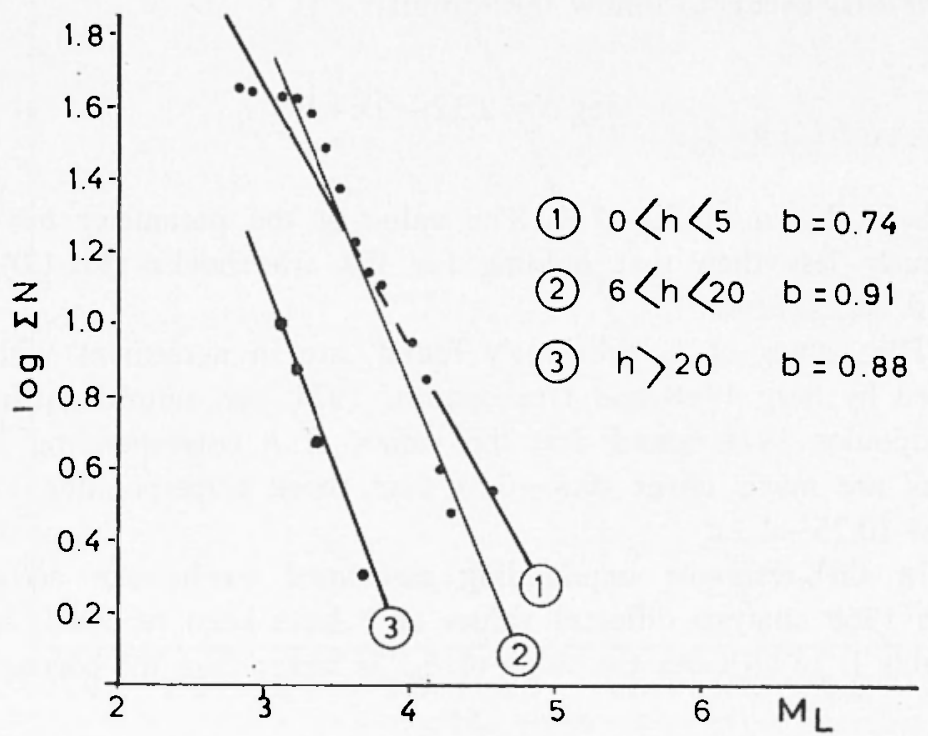

Fig. 9. Frequency - magnitude distribution at various dayers, for the first event. 
$b=0.74$ for the layer between 0 and $5 \mathrm{~km}$

$b=0.91$ for the next layers within 5 and $20 \mathrm{~km}$, constant, and

$b=0.88$ for higher depths.

The first layer corresponds to the depth of the sediments in the area.

The value of $b$ that was found for the layers 5 to $20 \mathrm{~km}$, indicates the presence of one layer, which was also assumed in the Model " $A$ " of Table III, given in paragraph 9.

These values of $b$ as decreasing with the depth are in agreement with the results of other investigators. Exception of this, constitutes, the present case with the unexpected small value of $b$ in the first layer, which, when smaller, is more suitable for homogeneous medium. This is due partly to the occurrence of the greater magnitude late aftershocks within the upper layer. The seasonal presence of the higher ground water table which results in the more homogeneous distribution of internal stresses, and the more complete stress release, is a strong evidence for the explanation of small $b$ value in the upper layer since the ground water is assumed to act as lubricating.

\section{Deformation Characteristics.}

The deformation in the aftershock zone has been calculated using the following formula given by Bath and Duda 1964:

$$
\log D=5.17+1.46 M
$$

where $D$ is the deformation in $\mathrm{cm}^{3}$.

The cumulative deformation $\Sigma D$ of the first sequence starting on June 31, 1975 was calculated and plotted versus time in Fig. 10. As it is seen from this figure, the sequence shows two phases, the compressional phase and the shear one. The energy in the compressional phase is released by small aftershocks and the corresponding deformation is expressed by the relation:

$$
\Sigma D=\{0.17+3.83 \log t\} 10^{11}
$$

The second phase consists of two branches; the first branch starts at 0.2 days and lasts for about 10 days after the main shock. The second 
branch begins with the occurrence of a magnitude $M_{L}=3.4$ earthquake, on fuly 14,1975 . The third branch includes a largest "late aftershock " of magnitude $M_{L}=4.6$. After the occurrence of this shock

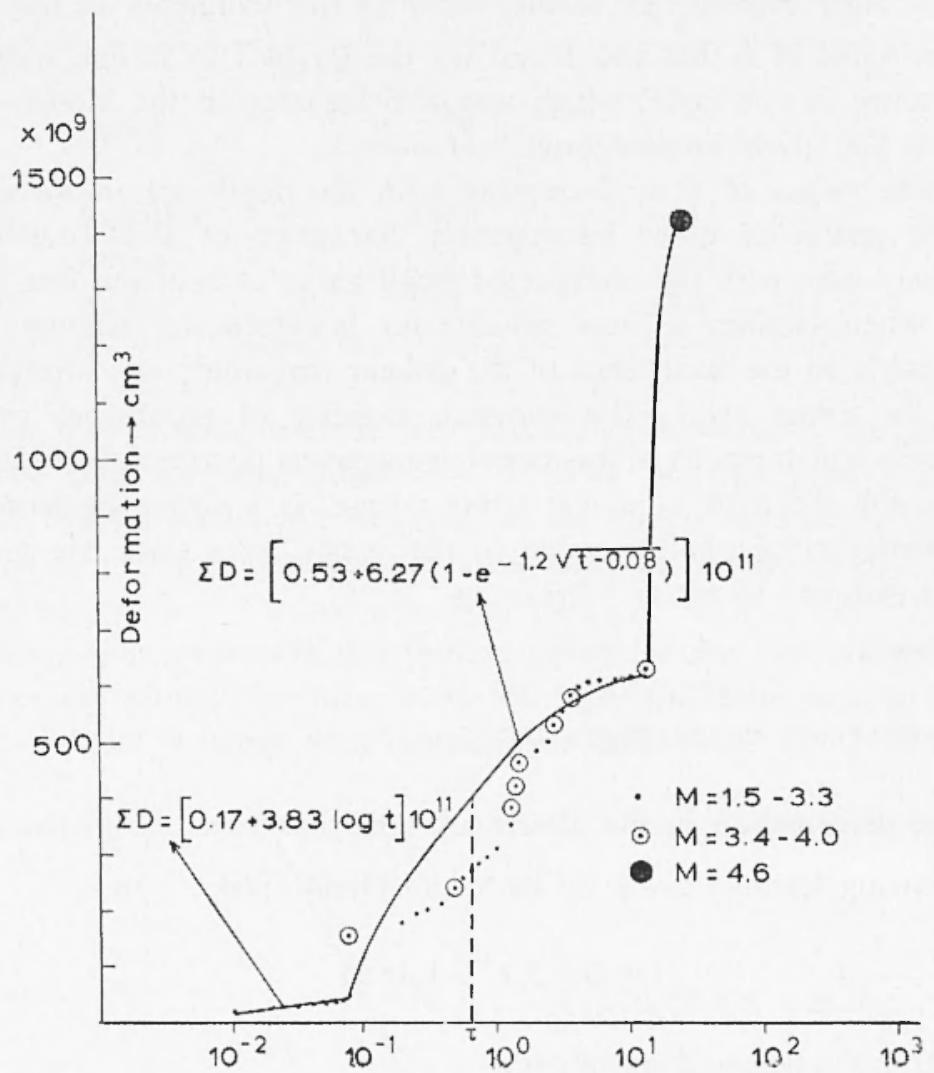

Fig. 10. Deformation characteristics of the aftershocks of the Earthquake of June 30, 1975.

the earthquake activity increased abruptly. From this, one may conclude that most of the shocks of the third branch probably are due to a different seismic volume. This is supported by the fact that the epicenter of the «late aftershock" differs from that of the main shock.

The first branch of the second phase is expressed by the relation:

$$
\Sigma D=\left\{0.53+6.27\left(1-e^{-1.21 / \overline{t-008}}\right)\right\} 10^{11}
$$

The relaxation time for the first sequence is 0.7 days. 
The cumulative deformation $\Sigma D$ of the second and third sequences are plotted in Figs $11 a, b$ respectively. The third aftershock sequence shows two phases as well, with one branch each, though the second sequence shows only one phase, the compressional one. This is due to the fact that almost at the end of its compressional phase the shear phase has been overlaped by the third aftershock sequence.

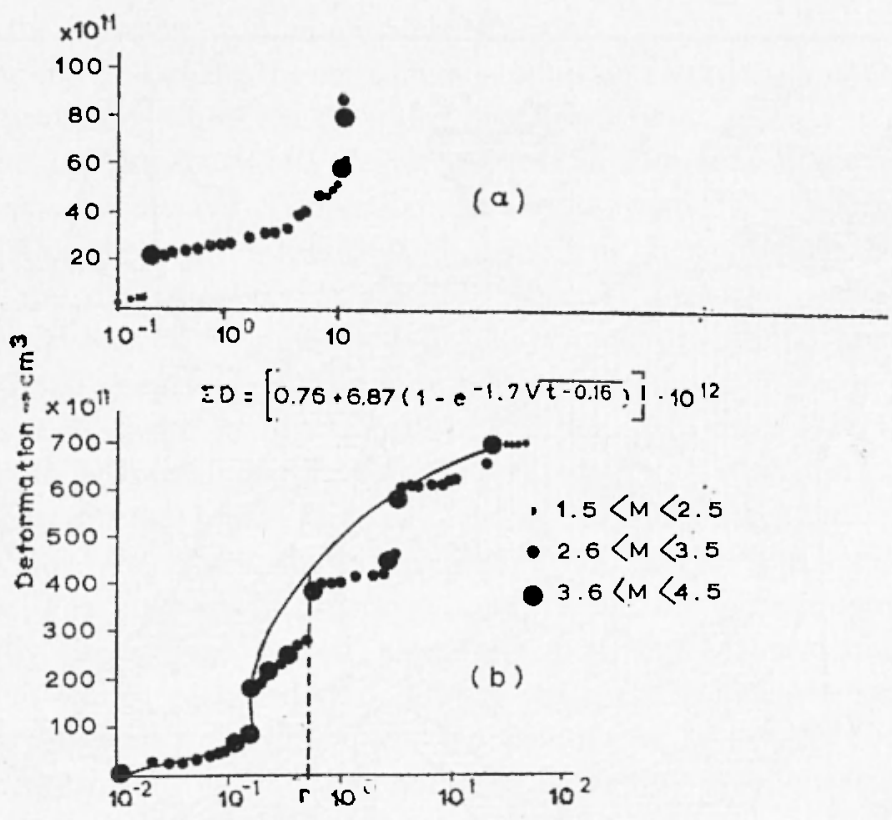

Fig. 11. Deformation characteristics of the aftershocks of the Earthquake of December 21, 1975 (a) and December 31, 1975 (b).

The shear phase of the third sequence is expressed by the equation:

$$
\Sigma D=\left\{0.76+6.87\left(1-e^{-1.17 /(\overline{-0.16}}\right)\right\} 10^{12}
$$

The relaxation time of the third sequence was found equal to 0.5 days. 


\section{Comments and treatment of macroseismic data.}

\subsection{Intensity distribution and focal depths.}

The isoseismal maps for the June 30 and December 31, 1975 earthciuakes are presented in Figs 1 and 12 respectively.

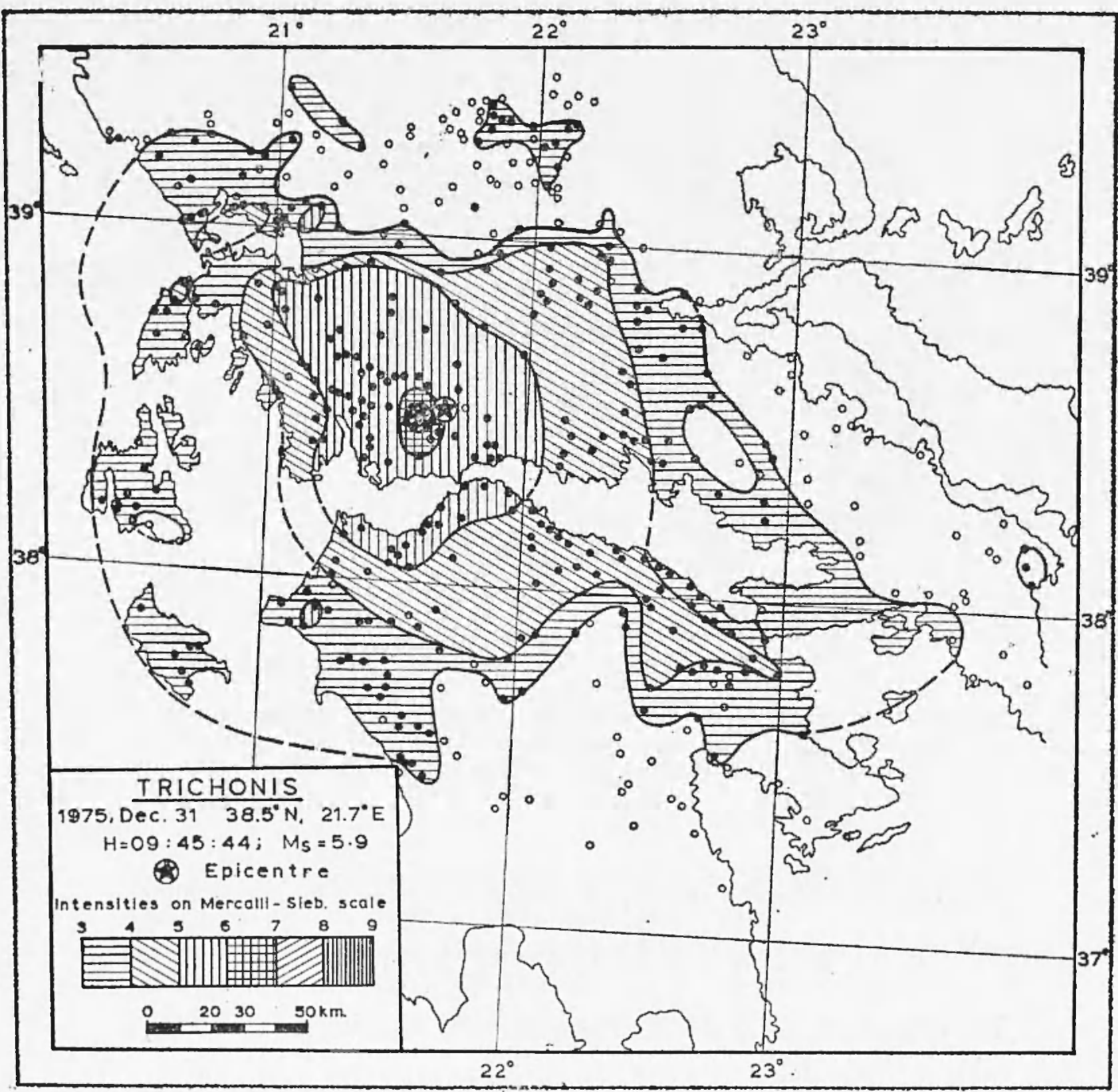

Fig. 12. Isoseismal map for the Earthquake of December 31, 1975. 
In the epicentral regions the maximum accelerations can be estimated, after Galanopoulos 1971, by the formula holding for the Greek area:

$$
a_{g}=0.26-0.1 I_{0}+0.01 I_{0}^{2}
$$

where $a_{g}$ the effective earthquake ground acceleration in units of gravity and $I_{0}$ the intensity in Mercalli-Sieberg scale.

For the first event the maximum ground acceleration was estimated to be $a_{g}=0.08 \mathrm{~g}$ while for the third one $a_{g}=0.10 \mathrm{~g}$.

The isoseismals of VI degree are of an elliptical form with the major axis to the $N-S$ direction, for both events. The difference in the relation between intensity and respective area most probably is due to the difference of earthquake depths of the two events. Thus, for greater than $V+$ intensities, the corresponding area is greater for the first and deeper event, than for the second one.

As it is shown in Figs 1 and 12 the boundary lines of III degree present an abnormal distribution. To the west, the shock reached the west coast of the Ionian Islands, Leukas, Cephalonia, Zante.

Northwards, the shock shows an abrupt decrease in the intensity of shaking. The intensity attenuation, occurs when the seismic waves and especially the surface waves, pass through fracture zones. The same picture is shown eastwards too. To the south the III degree isoseismal presents a clear elongation to the southwest and east coast of Peloponnesus. The shock was not felt in central Peloponnesus particularly in the front of the thrust belt between the Olonos-Pindus and Tripolis zones. The focal mechanism is also an important factor for the distribution pattern of the macroseismic effects.

In the areas, where the intensity was between III and IV, four " islands" of minor intensity may be observed, where the shock was not felt and "kernels» with intensity III - IV which lay out of the area bounded by the isoseismal line of III degree.

The determination of the coefficient of intensity attenuation $n$ and focal depth $h$ has been performed with the help of the theoretically computed master curves after Sponheuer 1960 and Shebalin 1972. In order to check the $n$ values, thus determined, the following relations have been used, by correlating the isoseismal areas $S_{\imath}$ or the average 
radii $r_{i}$ of the outer isoseismal lines $(i \geq 3)$ after Shebalin 1972:

$$
\log \frac{S_{t}+1}{S_{t}}=-\frac{2}{n}
$$

or

$$
\log \frac{r_{i}+1}{r_{i}}=\frac{1}{n}
$$

The resulted mean values are $n=4$ and $h=10 \mathrm{~km}$ for both seismic events.

Using the following empirical formula after Karník 1971:

$$
M=0.6 I_{0}+\log h+0.4
$$

where $I_{0}$ the maximum observed M. M. Intensity, it was found $h=3 \mathrm{~km}$ for the first event and $h=2 \mathrm{~km}$ for the third one; and after Shebalin 1972 the equation:

$$
I_{0}=1.3 M_{L H}-3.5 \log h+3.8
$$

it was found $h=9 \mathrm{~km}$ for the first event and $h=7$ for the third one. The corresponding value of depth after Galanopoulos (empirical formula):

$$
\frac{r}{h}=1.47^{I_{0}-I}
$$

where $r$ the maximum radius of perceptibility, and $I$ the MM intensity, equal to 1.5 for the present cases,

was found $h=16 \mathrm{~km}$ for the first event and $h=11 \mathrm{~km}$ for the third one.

The instrumental values of depths were calculated 11 and $3 \mathrm{~km}$ respectively. From the comparison of the focal depths estimated by instruments and by macroseismic data it is observed that the empirical formula for estimation of focal depths after macroseismic data give just indicative values.

The calculation of the absorption coefficient $a$, of the region under consideration, for both events and for various azimuths was made after 
Sponheuer 1960 by applying the formula:

$$
a=\frac{\frac{1}{n}\left(I-I^{\prime}\right)-\log \frac{r}{r}}{\log e\left(r^{\prime}-r\right)}
$$

where $I, I^{\prime}$ the intensity of isoseismals $r, r^{\prime}$ the hypocentral distances of the corresponding isoseismals $I$ and $I^{\prime}$, respectively, and $\log e=0.4343$.

As a mean value for both events was found $a=0.01$ to the $N N W$ and $E$ directions and $a=0.02$ to the $S$ direction. The mean value was calculated from the original values of $a$, and was found $a=0.018$ for all directions.

\subsection{Fault plane solutions and source parameters.}

Most calculations of focal mechanisms have been done for earthquakes with magnitudes $M \geq 6$. The long period stations network is insufficient for shocks of lower magnitude level. Short period instruments are often competent for shocks of magnitude $M \leq 51 / 2$, mostly of local stations with magnification, high enough for reading the initial motion of the longitudinal waves.

The focal mechanism of the shocks has been calculated, from the first motion directions at all the stations of the Greek network and of the neighbouring countries. The solutions are shown in Figs 15, 14 and 15 for the events of June 30, December 21 and December 31, 1975, respectively, and in Table II. The values are in agreement with other independent data.

From the available geological data, the aftershock distribution pattern and the $B$ axis indicate that the $a$ planes, (see Figs 13, 14, 15) are the fault planes for the three events.

In order to estimate the fault length $L$ in miles the following formula was used after Housner 1969 according to existing data of Central America:

$$
L=1.82 \quad 10^{-2} e^{4}
$$

which, for the first event of $M=5.4$ yields $L=4.03 \mathrm{mi}$ or $L=6.5 \mathrm{~km}$ and for the third one of $M=5.9, L=6.6 \mathrm{mi}$ or $L=10.6 \mathrm{~km}$.

For the same as the above mentioned data, Bonilla 1970 elaborated as the best fit lines for all the points the following two equations for the estimation of the length of surface rupture $l$ in miles, and the 


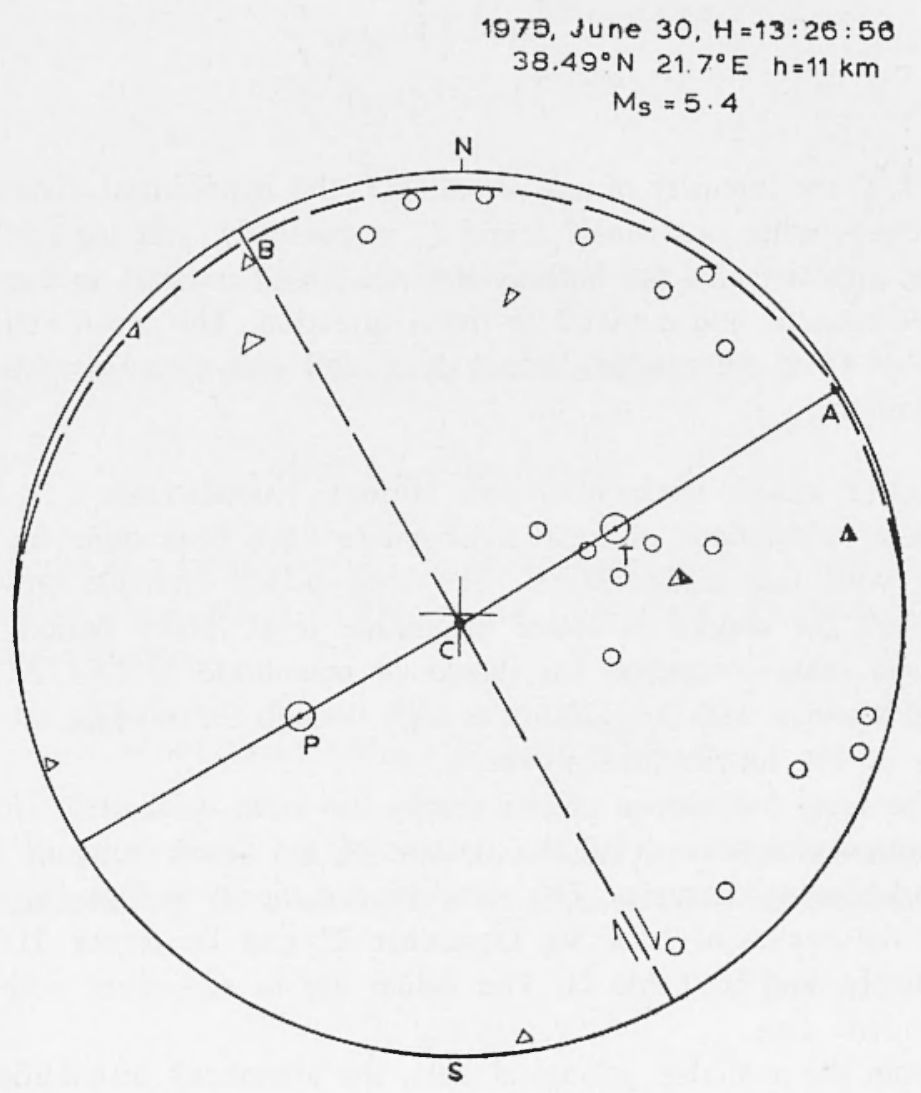

Fig. 13. Fault plane solution for the June 30, 1975 earthquake. 
1975, December $21 ; H=16: 07: 52$

$38.49^{\circ} \mathrm{N} \quad 21,75^{\circ} \mathrm{E} \quad \mathrm{h}=0 \mathrm{~km}$

$M_{s}=5 \cdot 8$

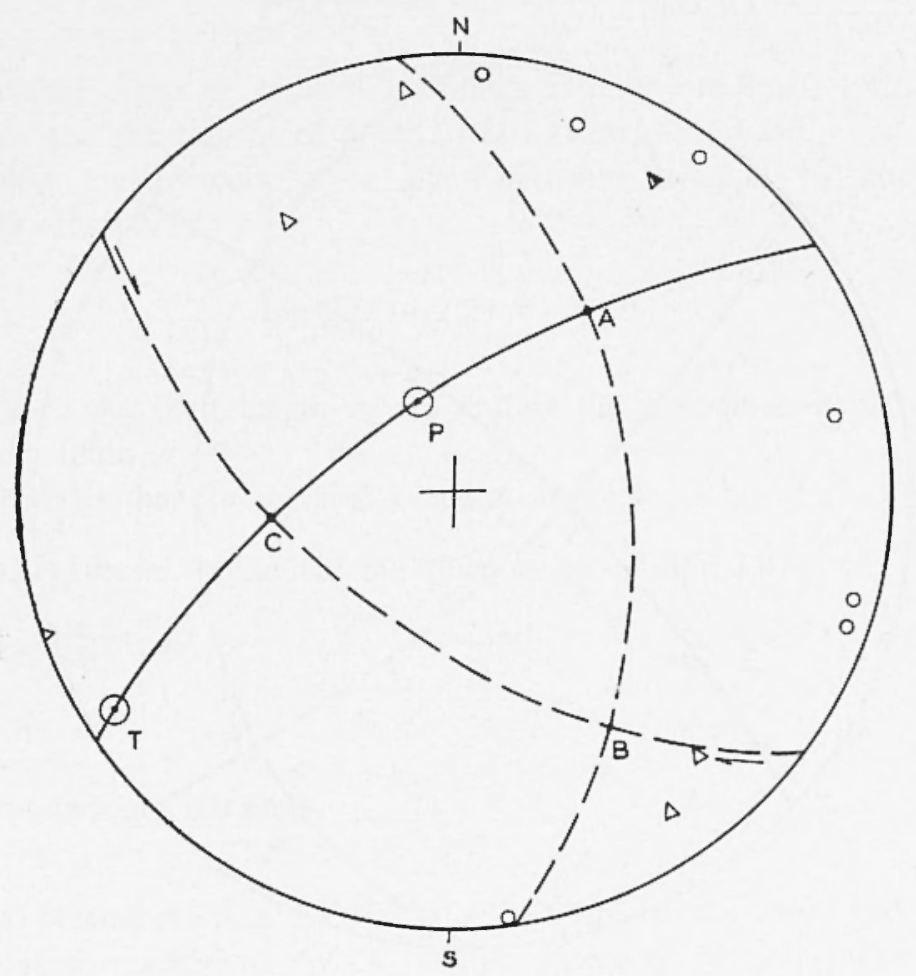

Fig. 14. Fault plane solution for the December 21, 1975, earthquake. 


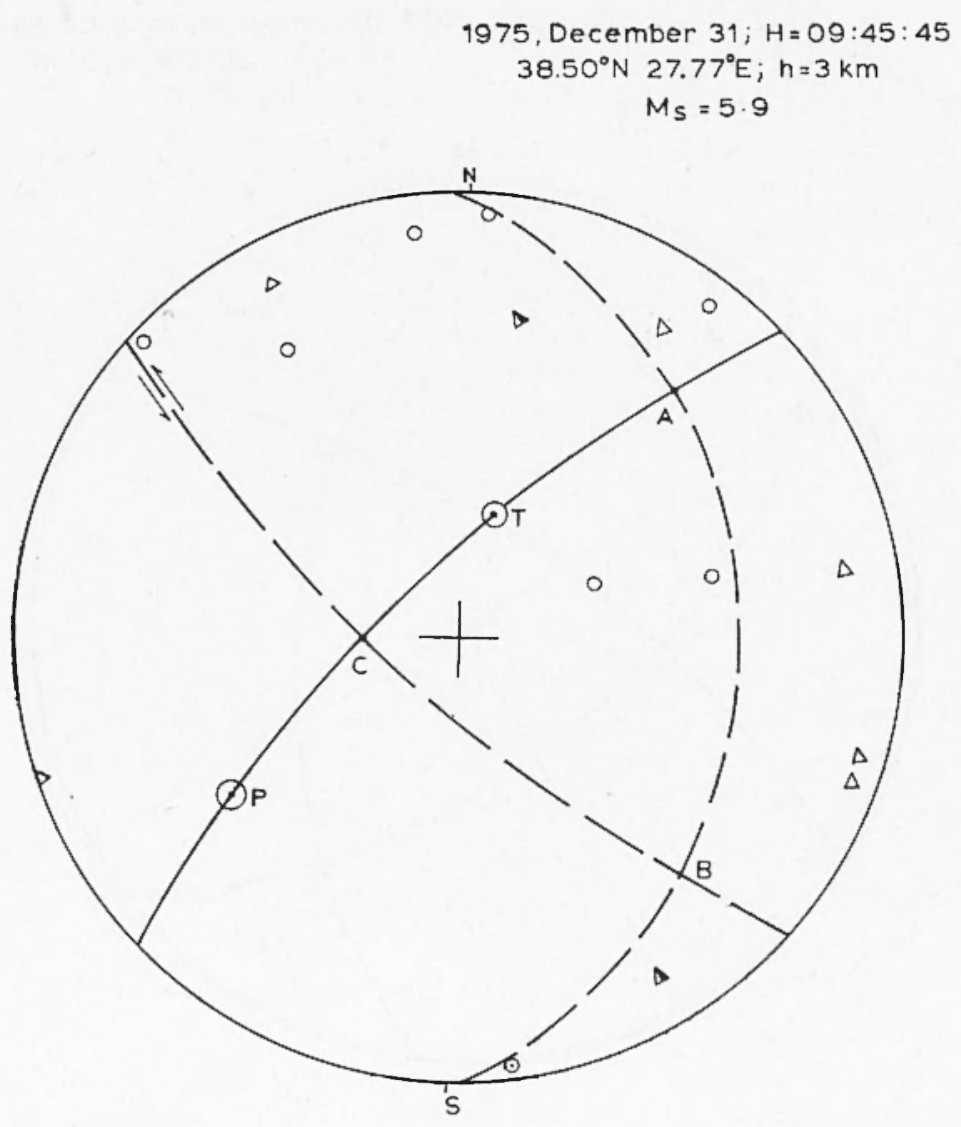

Fig. 15. Fault plane solution for the December 31, 1975, earthquake. 
maximum displacement $D$ in feet on the main fault at the ground surface:

$$
\begin{aligned}
& \log D=0.86 \log l-0.46 \\
& \log D=0.57 M-3.39
\end{aligned}
$$

For the first event of $M=5.4$ one finds that $D=14.8 \mathrm{~cm}, l=2.4 \mathrm{~km}$, while for the third event of $M=5.9, D=31 \mathrm{~cm}, l=5.1 \mathrm{~km}$.

Using the formula given by King and Knopoff as cited by Galanopoulos 1971:

$$
\log \left(L D^{2}\right)=2.24 M-4.99
$$

where $L$ is the fault length in $\mathrm{cm}$ and $D$ the maximum displacement along the fault, one calculates that for the first event of $M=5.4$ :

$L D^{2}=12.810^{6} \mathrm{~cm}^{3}$, while for the third event of $M=5.9$ :

$L D^{2}=168.310^{6} \mathrm{~cm}^{3}$.

\subsection{SEISMOSCOPE RECORDS.}

At Messologhi $\left(38^{\circ} 36^{\prime} N, 21^{\circ} 45^{\prime} E\right)$ where the first and third earthquakes reached a IV $-V$ degree intensity on Mercalli-Sieberg scale, a SR-100 Wilmot seismoscope recorded in the $N 120^{\circ} \mathrm{E}$ direction spectral velocity $13 \mathrm{~cm} / \mathrm{sec}$ for the first, Fig. $16 a, b$ and in the $N 130^{\circ} E$ direction spectral velocity $14 \mathrm{~cm} / \mathrm{sec}$ for the third event, Fig. $17 a, b$ respectively.

The seismoscope at Messologhi is instlled on the elevated by $1.5 \mathrm{~m}$ ground floor of the one story town hall. The foundation soil consists cif a very soft peat, sandy and silty clays, sediments of a drained lagoon.

It is worth while to note here that the directions of the main axes (if both records and their shapes as well, are homologous to the disIribution pattern of the isoseismals of the $\mathrm{V}$ and IV degrees as are presented in Fig. 1 and Fig. 12 respectively. 

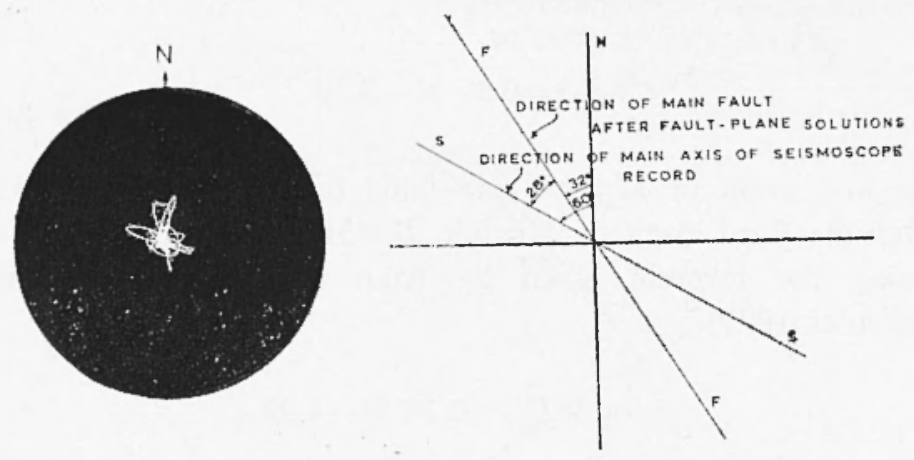

Fig. 16. Correlation of seismoscope record with fault - Plane solutions and shape of Pleistoseismic area of June 30, 1975, earthquake.
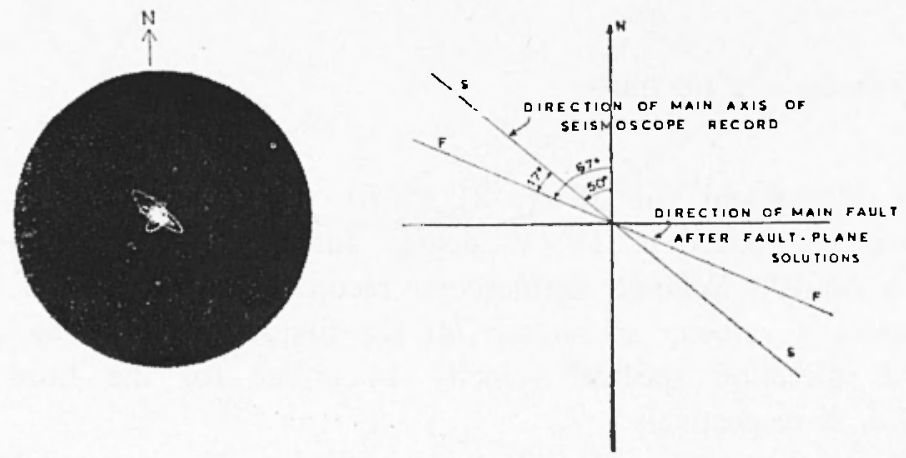

Fig. 17. Correlation of seismoscope record with fault - Plane solution and shape of Pleistoseismic area of December 31, 1975, earthquake. 


\subsection{COMmEnTARY ON THE INTENSITY DISTRIBUTION PATTERN.}

The macroseismic effects depend upon several factors, the more important of which are magnitude, focal depth and hypocentral distance, radiation pattern, propagation of waves through the geologic strata, soil conditions, duration and frequency bandwidth of shaking and the kind of building constructions related also to the extend of their exposure to previous earthquakes.

The fault plane solutions for almost all events show that the plane of action, in which there are the kinematic axes $A$ and $C$ as well as the $P$ and $T$ axes, is oriented to the $N E-S W$ direction and has a vertical plunge. From these four axes, the axis $C$ is horizontal while $A$ is almost vertical. Either single or double coup.e of forces act at the earthquake focus, the radiation pattern and consequently the intensity distrtibution, must be elliptical. This elliptical form is apparent in the shape of the isoseismals of $\mathrm{V}$ and IV degree, as it is shown in Figs 1 and 12. From the authors' point of view a better explanation of the intensity distribution may be given by the upgoing directions of these four axes.

The relatively high intensity of VII + degree observed in the meizoseismal area is mainly due to the small focal depth and probably to the radiation pattern in the direction of the axes $A$ (vertival), $P$ and $T$.

To the authors' opinion the fault plane solution explains fairly well the elongation of the isoseismals to the southwest direction (Axis $C$ ). In the north and east direction the seismic energy is not trasmitted to a long distance although much energy is presumably radiated towards these directions. This is probably due to the presumed discontinuity in the upper strata along geologic zones of successive upthrustings, overthrustings and faults, which run along the central Greece, as it is shown in the tectonic map of Greece.

It is worth noting, that in the central Peloponnesus and especially in the thrust front line between the Olonos-Pindos and Tripolis geologic zones, a strong attenuation of the seismic energy is observed. This can be probably attributed to the poor transmission of the seismic energy from the underthrust to the upperthrust members of the folded zone. Complicated tectonics of the region reflects to the complicated shape of isoseismals. 
Tarle II

\begin{tabular}{|c|c|c|c|c|c|c|c|c|c|c|c|c|c|c|c|c|c|c|c|c|}
\hline \multirow{3}{*}{ Earthquakes } & \multirow[b]{3}{*}{$\frac{5}{\frac{\Xi}{0}}$} & \multirow[b]{3}{*}{ 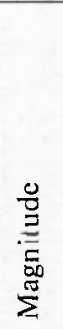 } & \multicolumn{2}{|c|}{$\begin{array}{c}\text { Axis } \\
\text { B }\end{array}$} & \multicolumn{6}{|c|}{ Plane of Action } & \multicolumn{10}{|c|}{$\begin{array}{ll}\text { Nodal } & \text { Lines } \\
\text { Plane }(a) & \text { Pla }\end{array}$} \\
\hline & & & \multirow[b]{2}{*}{$\stackrel{\overparen{D}}{\stackrel{D}{E}}$} & \multirow[b]{2}{*}{ 总 } & \multirow[b]{2}{*}{ 总 } & \multirow[b]{2}{*}{$\frac{a}{0}$} & \multicolumn{2}{|c|}{$\begin{array}{l}\text { Axis } \\
\mathrm{P}\end{array}$} & \multicolumn{2}{|c|}{$\begin{array}{c}\text { Axis } \\
\text { ' } \mathrm{T}\end{array}$} & \multirow[b]{2}{*}{$\frac{y}{\vec{E}}$} & \multirow[b]{2}{*}{$\stackrel{\circ}{a}$} & \multicolumn{2}{|c|}{$\begin{array}{c}\text { Axis } \\
\mathrm{C}\end{array}$} & \multirow{2}{*}{$\begin{array}{l}\text { Kind of } \\
\text { Faulting }\end{array}$} & \multirow[b]{2}{*}{ 竞 } & \multirow[b]{2}{*}{ 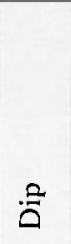 } & \multicolumn{2}{|c|}{$\underset{A}{A x i s}$} & \multirow{2}{*}{$\begin{array}{l}\text { Kind of } \\
\text { Faulting }\end{array}$} \\
\hline & & & & & & & 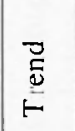 & 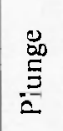 & 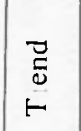 & $\begin{array}{l}\stackrel{\Xi}{0} \\
\Xi \\
\Xi \\
\Xi\end{array}$ & & & 胥 & $\stackrel{\substack{a \\
\Xi}}{\Xi}$ & & & & 胥 & 总 & \\
\hline $\begin{array}{l}\text { 1975, June } 30 \\
H=15: 26: 56 \\
38.49^{\circ} \mathrm{N}, 21.7^{\circ} \mathrm{E}\end{array}$ & 11 & 5.4 & $330^{\circ}$ & $\rightarrow 0$ & $60^{\circ}$ & $88^{0}$ & $237^{0}$ & $44^{\circ}$ & $62^{0}$ & $46^{0}$ & $150^{\circ}$ & $89^{0}$ & $195^{\circ}$ & $88^{0}$ & $\begin{array}{l}\text { Reverse } \\
\text { Dip-Slip } \\
\text { Dextral }\end{array}$ & $86^{0}$ & $2^{0}$ & $60^{\circ}$ & $1^{0}$ & $\begin{array}{l}\text { Reserve } \\
\text { Dip-Slip } \\
\text { Sinistral }\end{array}$ \\
\hline $\begin{array}{l}\text { 1975, December } 21 \\
H=16: 07: 52 \\
58.49^{\circ} \mathrm{N}, 21.75^{\circ} \mathrm{E}\end{array}$ & 0 & 5.8 & $145^{0}$ & $25^{0}$ & $36^{0}$ & $90^{\circ}$ & $35^{0}$ & $82^{\circ}$ & $215^{0}$ & $11^{0}$ & $172^{0}$ & $46^{0}$ & $36^{0}$ & $36^{n}$ & $\begin{array}{l}\text { Normal } \\
\text { Dip-Slip } \\
\text { Sinistral }\end{array}$ & $125^{0}$ & $54^{0}$ & $262^{\circ}$ & $44^{0}$ & $\begin{array}{l}\text { Normal } \\
\text { Dip-Slip } \\
\text { Dextral }\end{array}$ \\
\hline $\begin{array}{l}\text { 1975, December } 31 \\
H=09: 45: 45 \\
38.49^{\circ} \mathrm{N}, 21.77^{\circ} \mathrm{E}\end{array}$ & 3 & 5.9 & $288^{\circ}$ & $22^{0}$ & $19^{0}$ & $68^{\circ}$ & $47^{0}$ & $50^{\circ}$ & $185^{\circ}$ & $32^{0}$ & $114^{0}$ & $80^{\circ}$ & $137^{\circ}$ & $65^{\circ}$ & $\begin{array}{l}\text { Normal } \\
\text { Dip-Slip } \\
\text { Sinistral }\end{array}$ & $47^{\circ}$ & $25^{0}$ & $24^{0}$ & $10^{0}$ & $\begin{array}{l}\text { Normal } \\
\text { Dip-Slip } \\
\text { Dextral }\end{array}$ \\
\hline
\end{tabular}


9. Seismotectonic StUdy and spatial distrifution of aftershocks.

Accurate determination of the location of epicenters has been made for all earthquakes registered with $M_{L} \geq 3.3$. A modified version of the HYPOLAYR computer program after Eaton 1969 was used for the earthquake location. In TABLE III the velocity model « $A$ » after Makris 1976 which was assumed for the calculation of $P$ wave travel times is shown. For the calculation of $S$ wave velocities a Poisson's ratio equal to 0.25 was used. In the whole compilation of the main shocks and their aftershocks the Greek network station parameters and data were used, as well as the recorded shocks by two portable, smokedpaper seismographs, Sprengether type MEQ-800, used by the authors one day after the main shock of December 31. 1975.

One of the two seismographs was installed at the most affected village, at Kato Makrynou, operating as master station, while the other was used as a satellite station around the meizoseismic area with a time synchronization to each other. The observations lasted four days and the total number of the recorded shocks exceeds 2000. The foci of the recorded aftershocks present a small shift as it is shown from the difference of arrival times between $P$ and $S$ waves.

TABLE III

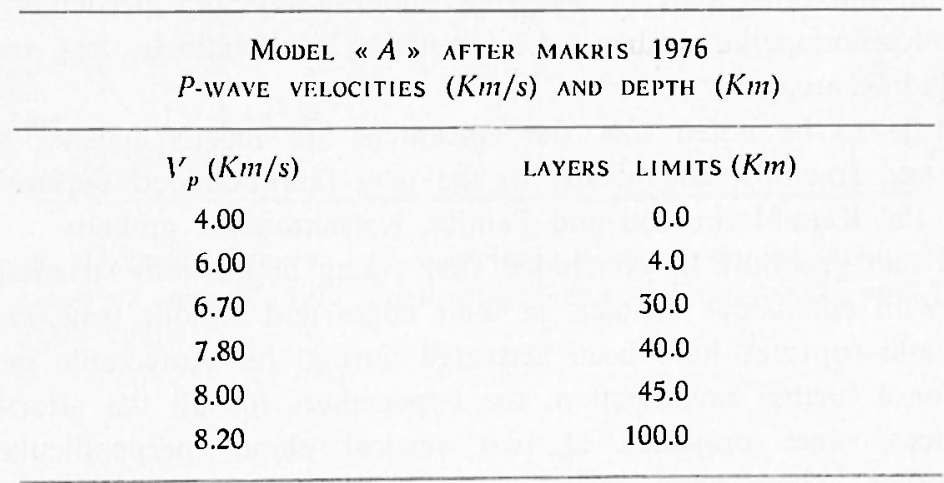


The diference oscillates between 1.2 and $2.0 \mathrm{sec}$, corresponding to an epiceniral distance between 6 and $10 \mathrm{~km}$, for the focal depth considered.

The affected region, belongs to the external tectonic units of the Hellenides; which shows an important tectonic activity during the middle Quaternary. In addition, many faults were created or reactivated during the following two stages:

a) The first stage, between the Calablian and middle Quaternary time, as evidenced by reverse faults or flexures is characterized by a compression striking $N E-S W$.

b) The second is the middle Quaternary stage, which is mainly characterized by normal faults along the anticlines.

Taking all these into account, it can be considered that this area from geotectonic point of view, is a very unstable one.

On the map of the tectonic features of the region the epicenters of 100 best located aftershocks are shown in Fig. 18. As it can be seen from this map, the mosaic pattern of faulting can be discriminated into three fault systems:

a) The first system trends $N E-S W$ and is perpendicular to the axis of anticlines.

b) The second system trends $E-W$ and

c) The third one trends $S E-N W$, parallel to the folds.

As it is shown from Fig. 18, the aftershock distribution pattern shows an northeast trend into the upper reaches of the Evinos River, northeastwards of the Pindus thrust. The epicenters are more concentrated in the inner part of the area under study and particularly in Famila-Katsantoneika graben; the clustering is relatively less in the surrounding area.

It is to be noted that the epicenters are mostly located along faults and fractures and mostly in the new fault-bounded depressions, as are the Kato-Markrynou and Famila, Katsantoneika grabens.

It can generally be concluded that young depressions, particularly those with anomalous contacts at their edges and regions traversed by faults and ruptures have been activated during the neotectonic period.

For a further investigation, the hypocenters for all the aftershock sequences, were projected to two vertical planes perpendicular to each other. These cross sections, oriented $E-W$ and parallel to the Pindos thrust (see Fig. 18), are indicated by $A-A$ and $B-B^{\prime}$ in Figs 19 and 20 , respectively. 


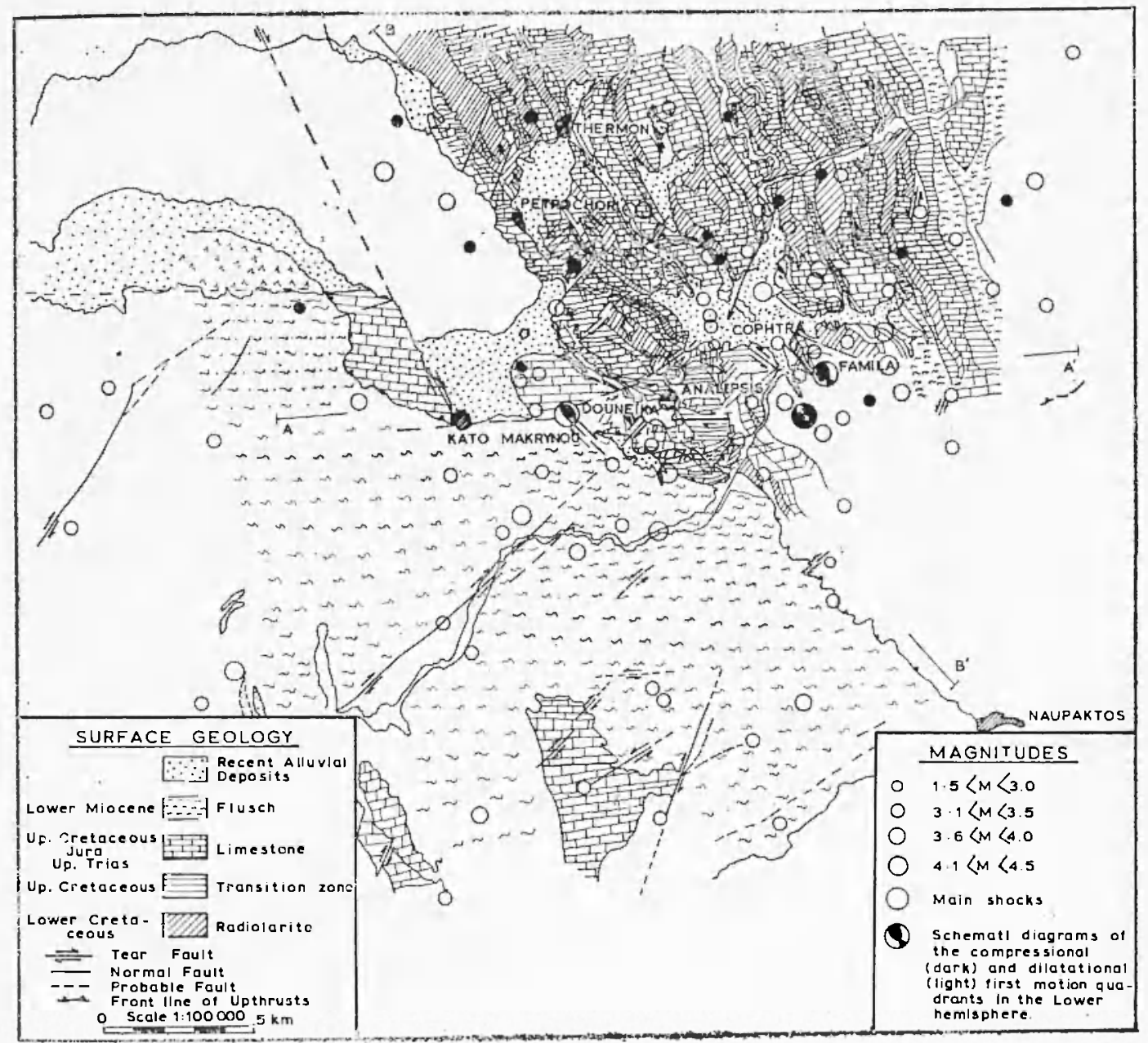

Fig. 18. Tectonic features and epicentral locations of the main Trichonis events of June 30, 1975 (Solid circles) and of December 21 and 31, 1975 (open circles). 


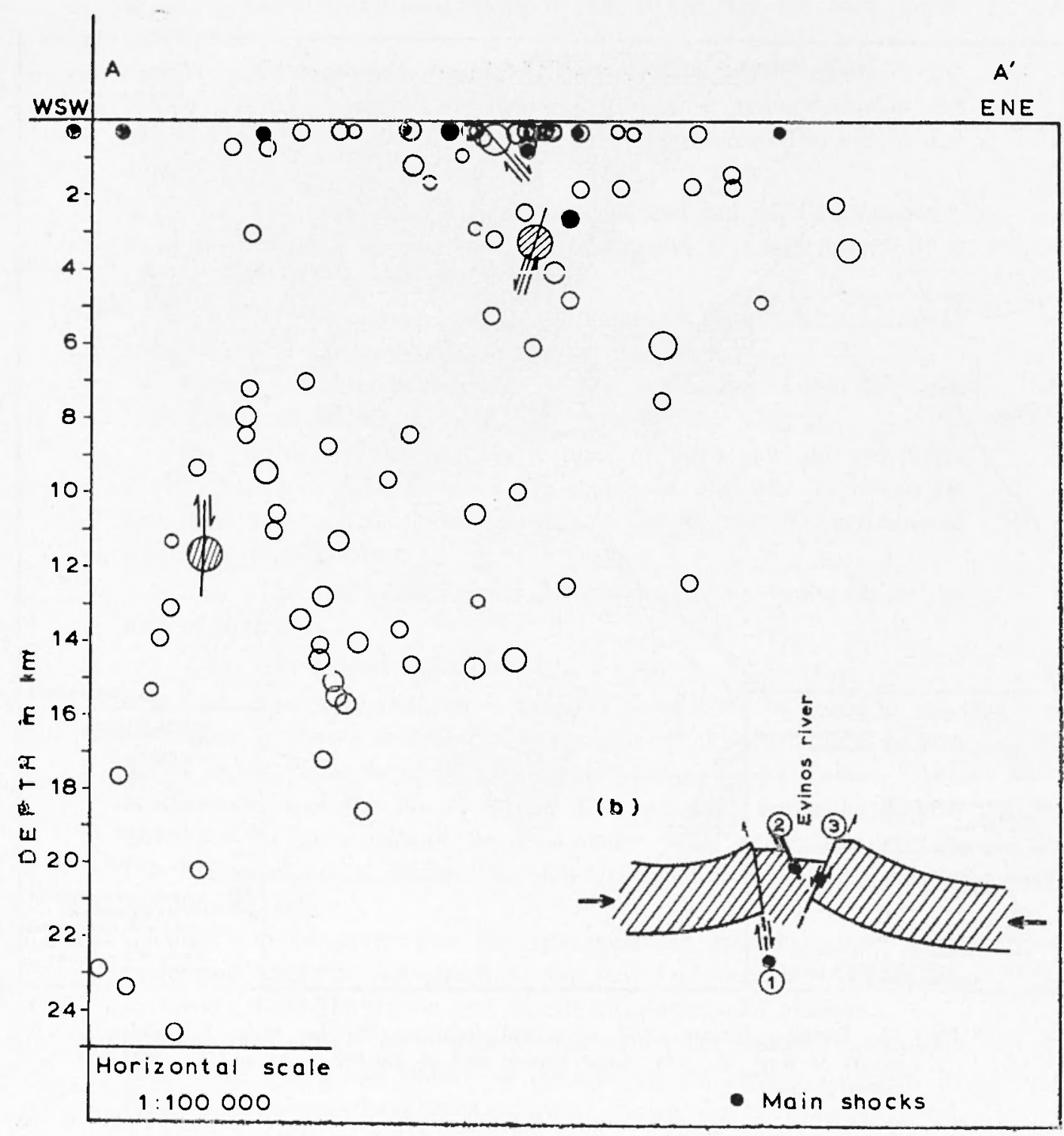

Fig. 19. Cross section $A-A^{\prime}$ with plot of aftershock hypocenters (Solid circles the event of June 30, 1975, and open circles, the aftershocks of Dec. 1975). 


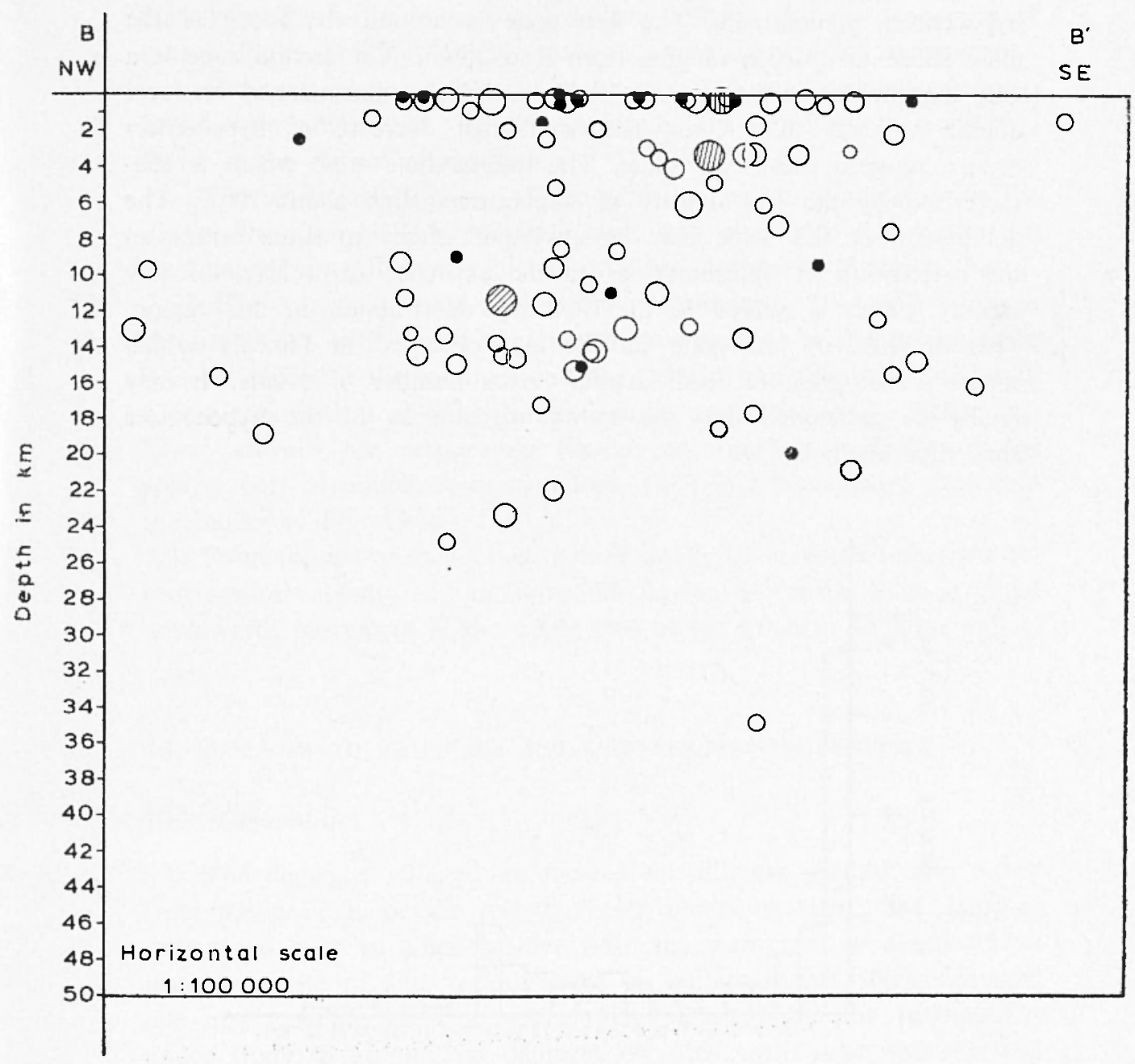

Fig. 20. Cross section $B-B^{\prime}$ with plot of oftershock hypocenters (Solid circles, the events of June, 30, 1975 and open circles, the aftershocks of Dec. 1975). 
In both projections of Figs 19 and 20 two clustering zones of hypocenters predominate. The first zone is around the focus of the main shock to a depth ranging from 9 to $20 \mathrm{~km}$. The second zone is a very shallow, between 0 to $6 \mathrm{~km}$. It is worthnoting that most of the focal depths are less than $5 \mathrm{~km}$, and a distinct decrease of hypocenters occurs between these two zones. The intermediate zone which is characterized by the less density of hypocenters dips about $20^{\circ} E$. The delineation of this zone may be attributed either to some errors on the calculation of epicenters, or to the existence of a layer of low rigidity which is related to the Cenozoic deformation in this region. This decrease of foci zone can be also observed in Fig. 21 which shows a histogram of focal depths versus number of events. It may finally be concluded that the spatial distribution of the hypocenters zone dips about $60^{\circ} \mathrm{W}$.

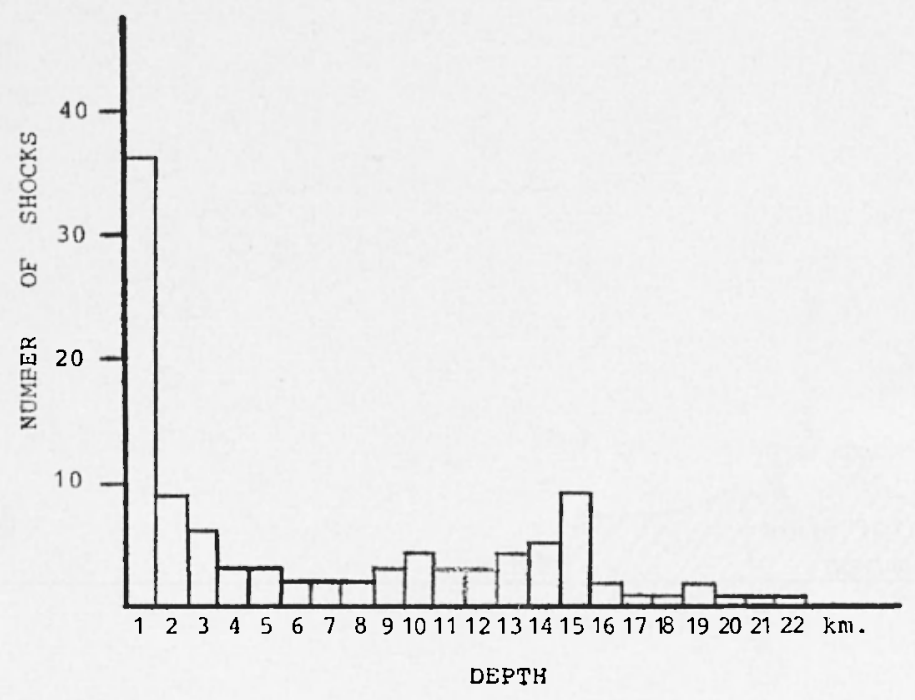

Fig. 21. A histogram of focal depths versus number of events.

From the fault plane solutions it can be observed a change in the kind of motion. The fault motion during the June earthquake was reverse and dextral, while in both shocks of December it was normal and sinistral. The epicenters of the last two shocks were 
located $5 \mathrm{~km}$ eastwards to the first one, at the southeast end of Katsantoneika - Famila graben (Cophtra Valley), in where a series of ncrmal faults, striking $N W$-SE, marks a sharp topographic escarpment.

The fault plane solutions for the two late shocks indicate normal faults with strike and dip almost similar to those of the observed faults at the surface of the area.

The westwards dipping of the nodal planes $a$ coincides with the dip of the aftershock hypocentral zone and also with the motion on the fault planes. All these evidences indicate that the focal region (No. 1, 2, 3 Fig. 19) is fatigued and strongly dislocated. The valley lies at the top of an anticline, which moved downwards. In the present case it is believed that the tectonics and the seismicity of the region is due to a continuous effect of compressional stress perpendicular to Hellenides. These stresses are responsible for an occasional subsidence of the central part of anticlines or synclines, as it is schematically shown in the model of Fig. $19 \mathrm{~b}$.

From the above mentioned, it may finally be concluded that the recent seismic activity of the Trichonis Region is caused from a slight downwards movement of the upper part of the Cophtra anticline valley.

\section{Damages to bUILDINGS AND ENGINEERING STRUCTURES.}

\subsection{Generalities.}

The demaged villages are located on different ground sites either from the geologic or the soil dynamics points of view. The damages are spread over an elliptical area with the main axis of about $15 \mathrm{~km}$ length. Inspite of the various kind of buildings that were damaged one may conclude that it was a general trend for the earthquakes under study to accumulate damages on sites with loose soil material of small to medium depth. In one case of deeper cohesionless soils the most of the buildings suffered quite insignificant damages, as it was evidenced at the village Pamfion (at about 3-4 km N-E of $\mathrm{K}$. Makrynou village). The increase of damages on sites with loose soil materials may be due to the following reasons:

a) Increase of the duration of the significant ground shaking.

b) Increase of the nonuniform foundation settlements. 
c) More uniform, in the frequency domain, ground shaking, which means increase of the number of peaks.

d) Increase of the displacements and in a minor percentage of the velocities of the ground shaking, Seed et al 1970 .

$e$ ) The predominant periods of the shaking increase, which in relation to the above $c$ and $d$, results to more apparent resonance phenomena of the structures with greater fundamental periods.

f) The effect of «secondary factors » of the body of the soil (water, compaction, overburden pressure etc.) to its dynamic behaviour is more pronounced, which results to different input motions even to one and the same building.

g) The deterioration due to the aging of buildings founded on loose soils is higher than that of buildings founded on rock.

As it has been shown by Seed at al, 1975, the ground acceleration is lower on sites of stiff soils and even lower on sites of deep cohesionless soils, at small epicentral distances than on rock. Inspite of the above $a$ to $g$ adverse conditions the very low accelerations that most probably appeared on the ground surface of the village Pamfion (site with deep cohesionless soil, as explained at the beginning of this paragraph) may explain the absence of any significant damage. On the other sites of rather small soil depths or near the boundaries where the inclined bed rock starts outcroping, the ground surface acceleration is higher which in combination with the above mentioned conditions $a$ to $g$ resulted to a drastic increase of the damages as is shown by Sieberg and cited by Galanopoulos 1971 and Seed at al, 1970. This is the case of a part of Kato-Makrynou village.

It is worthnoting here that an other part of Kato-Makrynou village is founded on flysch or limestone when outcroping. Although the ground surface accelerations are expected quite high as is shown by Seed et al, 1975 and Trifunac and Brady, 1976 the damages are very low. These observations give the ground to reaffirm also the remark made by Donovan, 1973 that: «... acceleration values when used alone are not an effective parameter for describing the damaging effects of earthquakes. Higher particle velocities and longer durations of shaking are believed to be the reasons for these greater damage areas". 
10.2. Structural CONDitions, general Classifcation of DAMAGEs.

The types of the structural load carrying systems used in the buildings almost characterize the time of the erection of the building, so that the buildings of the region under study may be divided into the three categories: Old, Newer and Contemporary buildings. Their general characteristics and seismic behaviour is briefly given as follows:

\section{a) Old Buildings.}

These are one or two story stonemasonry houses with reinforcing layers on the stcneworks out of wood or bare steel bars of various cross sections. Sometimes there are vault structures with wooden roofs. The roofs are out of hollow, french type clay tiles or thin schist plates which have a considerab'e weight. Usually the floor, of the two story houses, is wooden. In order to obtain on both sides of the walls plane surfaces, the two sides of the walls were constructed almost separately without any connection to each other while the mortar which was poured inside was of bad quality. Many structures in this category are built without any mortar (dry masonry).

The period of the erection of these category of structures may be dated as before 1945. One may estimate that, as a mean, these structures have been exposed before Iune, 1975 to at least three earthquakes with each one being almost equal to the earthquake of Iune 50, 1975. That means that these structures, after the third earthquake of December 31, 1975, are exposed to about six such earthquakes.

The partitions of the buildings are out of light timber work (bagdati) which do not add any structural connection among the exterior and rest load carrying walls.

These buildings suffered the most damages. This may be attributed due to two facts. One is the above mentioned bad way of construction and the other is the entire lack of repair due to previous minor or not earthquakes and maintenace due to aging of the structures.

The structures of this category which, due to the earthquake of June 30, 1975, considerably crakcd and were not repaired. as it should be, half of totally collapsed during the late shocks, as it is shown in Fig. 22. 


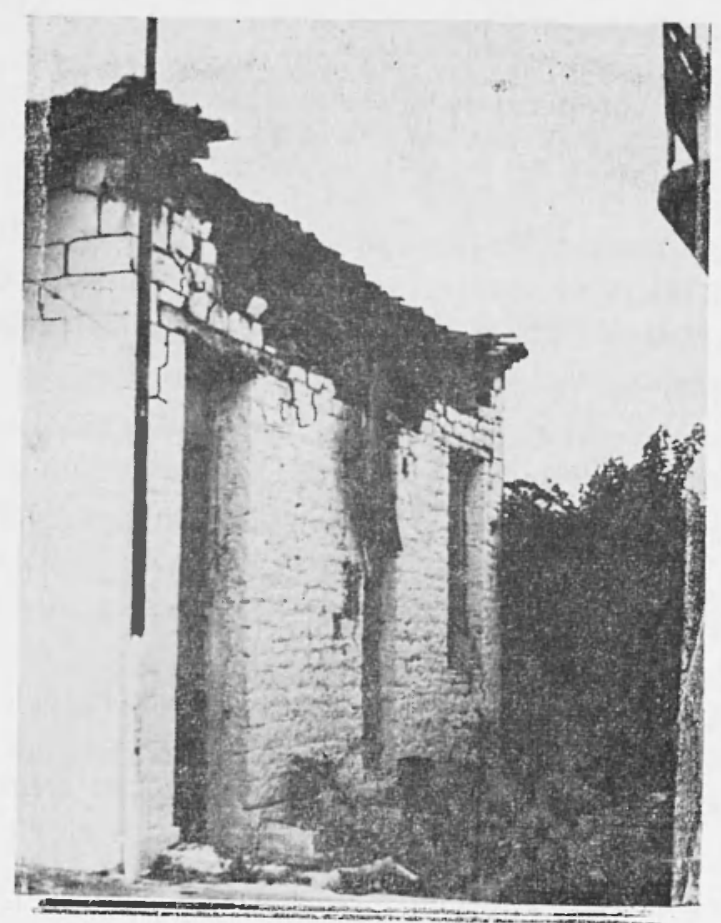

(a)

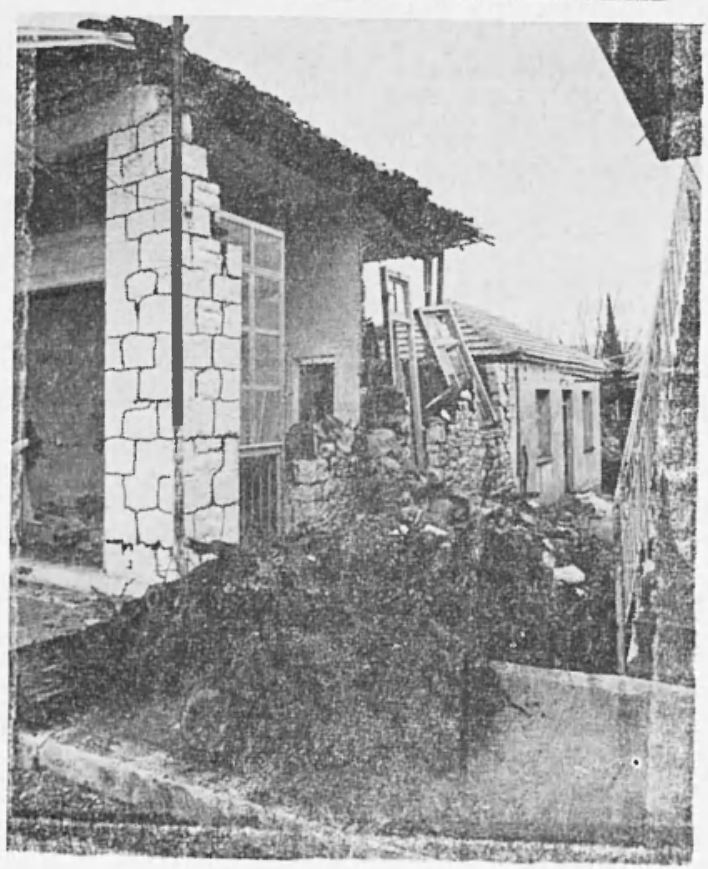

(b)

Fig. 22. Old house half collapsed after the third earthquake (b). It was not repaired after the first earthquake $(a)$. 
On the contrary, which must be emphasized in the present study, those of the buildings that were carefully repaired due to previous earthquakes, showed a very good response and strength during the late earthquakes. One may pcint out here that the seismic behaviour of this kind of repaired structures is better than one could expect. An explanation of this, may be the ability of the well repaired structures for alsorption of higher energy, while their load carrying walls do not lose their strength and externally do not show much cracking during a next earthquake. But this external good appearance of the walls may be fatal for the structures against future seismic activity.

\section{b) Newer Buildings.}

These are one to three story stone or brick masonry houses with reinforcing leyers on the stone or brickworks of limited length in general. These reinforcing layers are reinforced concrete or bare steel bars of various cross sections, at the places of lintels. The roofs are wooden with hollow or french type clay tiles. The trusses of the roofs lie on a layer out of cement-lime-sand mortar. The construction of the buildings of this citegory is better than that of the previous category. Most of these buildings have been constructed in the period between 1945 and 1960. The partitions are usually brickwalls. These structures may be said that have been exposed before June, 1975 to at least one earthquake equal to that of June 50,1975 . The majority of these structures responded to the subsequent two earthquakes with no significant damages. The most of these damages were due to constructional errors and being rather unimportint were not repaired after the first earthquake. But during the last earthquake of December 31, 1975, these structures suffered heavy damages. This may be observed in Fig. 23.

\section{c) Contemporary Buildings.}

The construction of these buildings is according to earthquake proof recpuirements and the yielding since 1959 National Code for aseismic constructions. These structures are one to three story stone or brick masonry houses. For the construction was generaly used strong cement lime-sand mortar. The reinforcing leyers are put at the levels of lintels, window and door sills forming at most a close circumferencial belt out of reinforced concrete. In this category belong also the buildings 


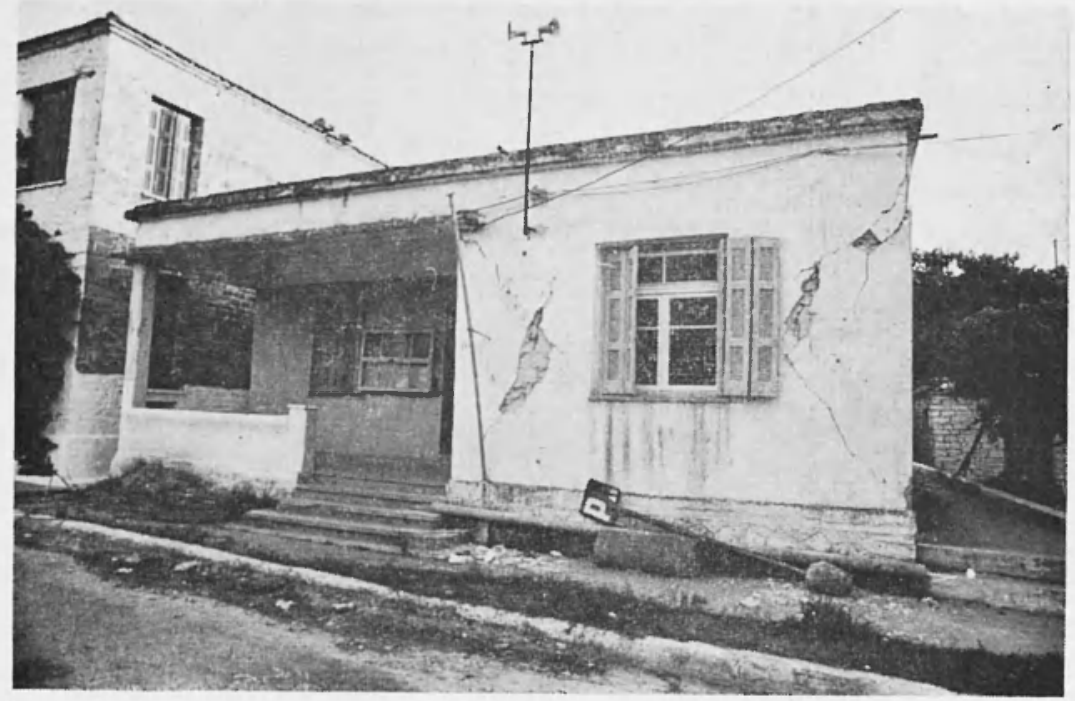

(a)



(b)

Fig. 23. Newer building not repaired after the first earthquake (a) were heavily damaged after the third earthquake (b). 
with a reiforced concrete load carrying structural system with infill brickwalls. In both cases of masonry or reinforced concrete buildings the partitions are brickwalls with no or a very loose connection to the load carrying system. The roof is usually constructed as a reinforced concrete slab.

For the occurred series of earthquakes in the region under study and the way of construction of the buildings, the overall behaviour of the contemporary stone or brick masonry structures may be considered as better compared to what one could expect from the modern buildings with a reinforced concrete load carrying system and infill brickwalls. This may be attributed also to the higher damping capacity that the first category of structures presents compared to the latter one. The influence of the damping in reducing the response of the structures is even more apparent for epicentral regions where the high acceleration values are associated with high frequencies.

At the structures of the above mentioned latter case one generally may observe the following pattern of damages: Dislocation of the brickwalls (partitions or infill walls) from the load carrying system as it is shown in Fig. 24. Cracks and deterioration of the concrete of staircases and mainly at their connections at floor levels, and relevant structural parts. This case is representatively shown in Fig. 25. Explanation of this behaviour is given by Angelides and cited in Kokinopoulos and Tasios 1966.

In most cases appeared horizontal cracks at the columns and vertical cracks at the slabs and beams. These may be schematicaly shown in Fig. 26. Visible influence of various at first sight of «minor importance factors ", as for example, the existance of a vertically stiffening element with a greater rigidity, non symetrically sited on the plan, has caused serious damages to the structure and the load carrying system. These are due to considerable rotation (cracks $c_{1}$ ) around a vertical axis and an horizontal displacement that the top of the structure underwent during the earthquake. The increase of the rigidity of vertical elements may be due to structural, architectural or use reasons. A very common case of increasing their rigidity, is the reduction of the effective height $H$ of the element, by placing the lintels and window sills. Since the rigidity $K$ is expressed according to Fig. 27 by the relation [28].

$$
K=\frac{E \cdot B \cdot D^{3}}{H \cdot\left(H^{2}+3 D^{2}\right)}\left(t m^{-1}\right)
$$




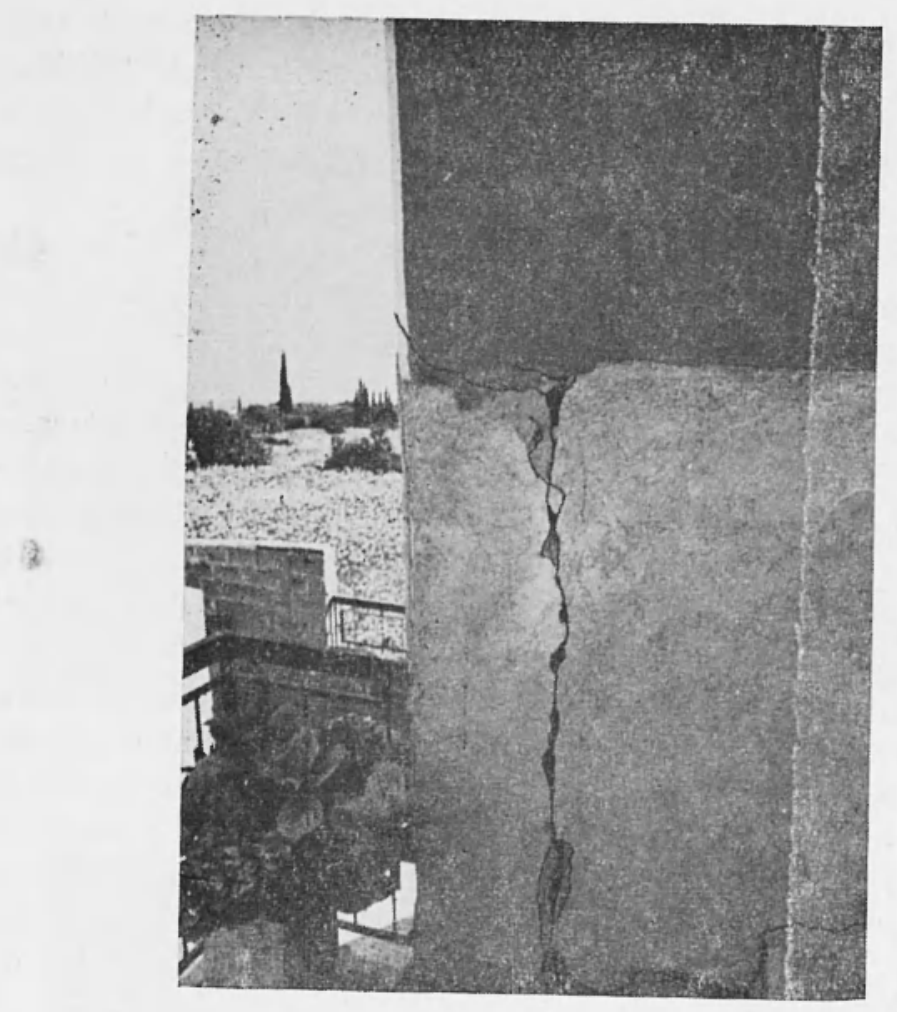

(a)

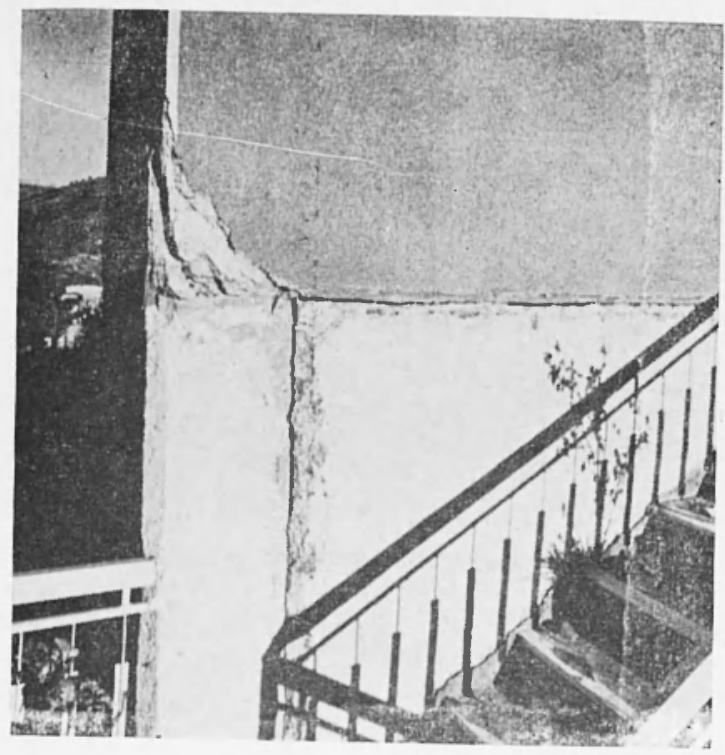

(b)

Fig. 24. Separation of the brickwalls from the reinfored concrete lond carrying system, after the first $(a)$ and the third (b) earthquakes respectively. 


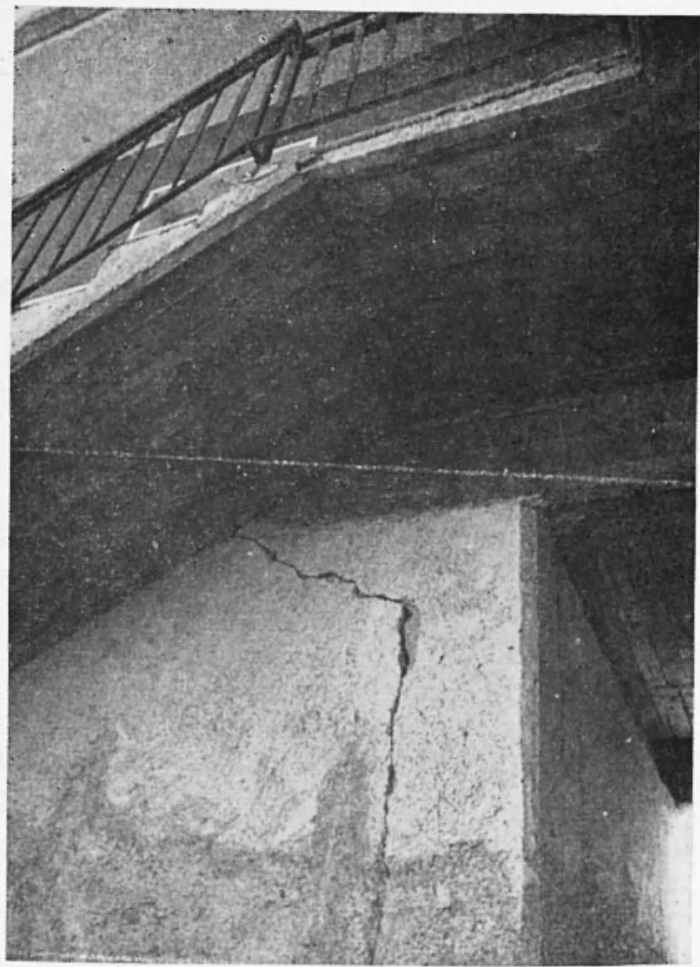

(a)

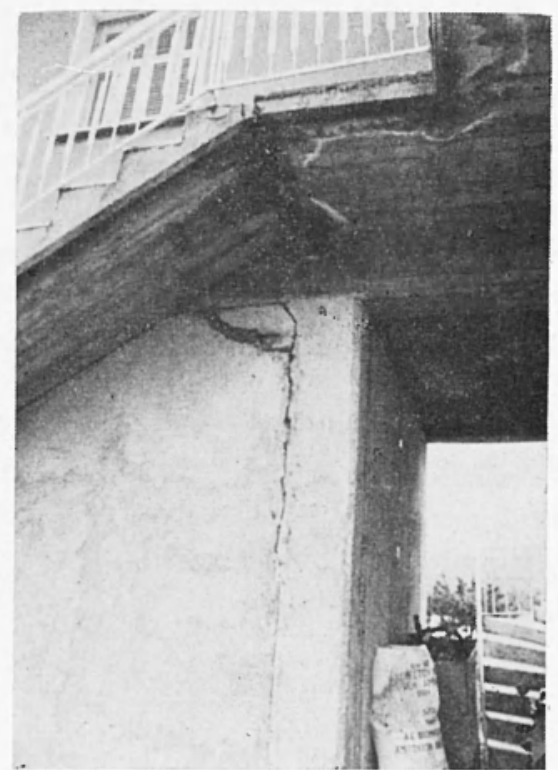

(b)

F.g. 25. A view from down of the staircase of fig. 29, after the lirst $(a)$ and third $(b)$ earthquakes respectively. 


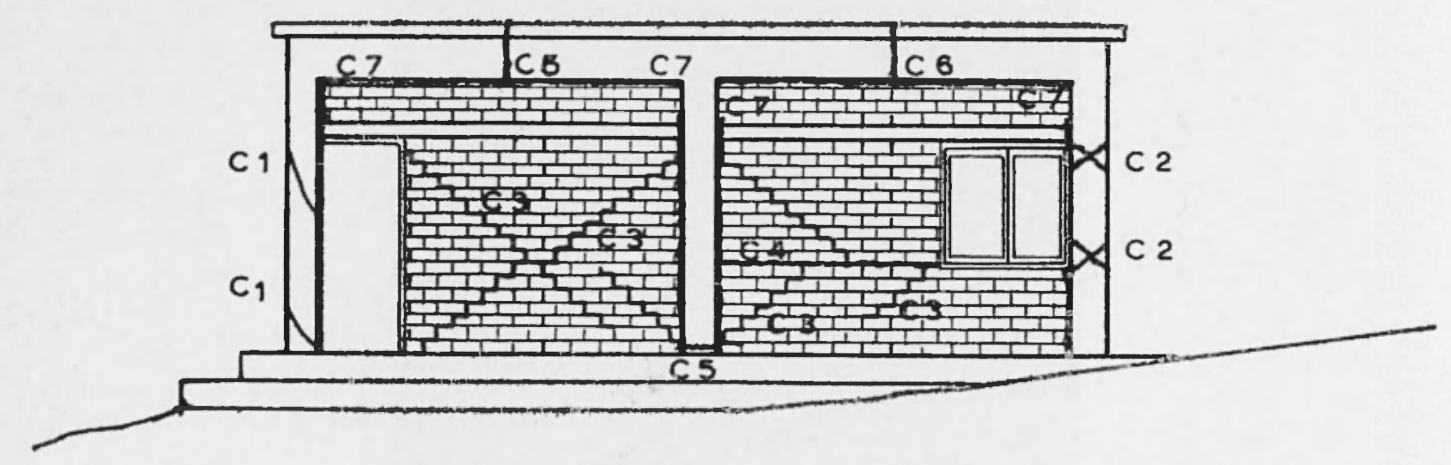

Fig. 26. Typical cracks of contemporary houses mostly built according to earthquake proof requirements $C_{1}$ : tortional cracking, $C_{2}$ : shearing and bending cracking, $C_{3}$ : diagonal pure shearing cracking, $C_{4}$ : bending or pure tentional cracking, $C_{5}$ : circumferential tentional crack, $C_{6}$ : vertical cracks at slabs and beams, $C_{7}$ : dislocation of the brickwalls from the load carrying system.
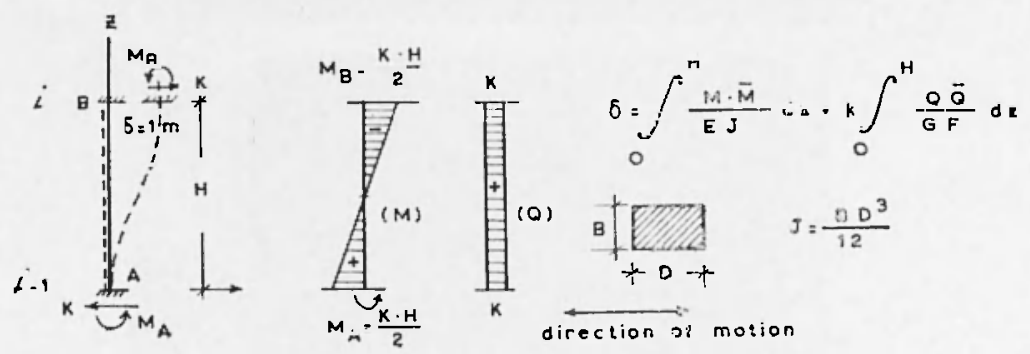

Fig. 27. Diagrams for the calculation of the rigidity $K=1 / \delta$ of an elastic member adjoining to levels $i$ and $i-1$ according to the "Shear building hypothesis ». 
where $E$ : the modulus of elasticity of the material of the elastic member $t m^{-2}$.

$B, D$ : the two dimensions of the cross section of the member perpendicular and parallel to the direction of motion respectively.

$H$ : the effective height of the elastic member within which the displacements of the adjacent floor levels will occur.

By reducing the effective height $H$ the rigidity $k$ increases almost by the cube power of $H$, which is more evident for rather slender members.

In almost no one case this abrupt increase of the rigidity and henceforth the redistribution of the seismic loads has been taken into account during the aseismic or structural desing of the structures. This is due to either the complexity that the adequate design aquires, or due to the alterations or additions made after the initial drawings. The cracks $c_{1}$ of Fig. 26 are a typical pattern due to the above mentioned rotation of the structure.

In the epicentral regions where the vertical vibration was the dominating character of the ground motion, was observed that, in some cases, the vertical reinforcing bars at the top and bottom of concrete columns were curved outwards as it is shown in Fig. 28, and in any direction of the cross section of the columns, related also to the circumferential cracks $c_{5}$ of Fig. 26. The outwards curving of the reinforcing steel bars may also be attributed to an excessive tension due to bending of the respective reinforced concrete cross section, away from the epicentral region. In the latter case the bending is almost undirectional and do not appear the circumferential cracks $c_{5}$.

The inevitab'e construction joints during the bedding of concrete responded very badly against the earthquakes under study, due to the absence of any or adequate connection of the two adjacent parts. A characteristic damage of this kind is shown in Fig. 29.

The authors want to point out that the contemporary, one to three story, buildings, constructed out of a flexible reinforced concrete load carrying system are subject to damages very of ten and these damages in the most cases are due to the effects of «minor importance factors". On the contrary the stiff, one to three story, reinforced concrete buildings suffered almost nothing during the under study seismic series. 


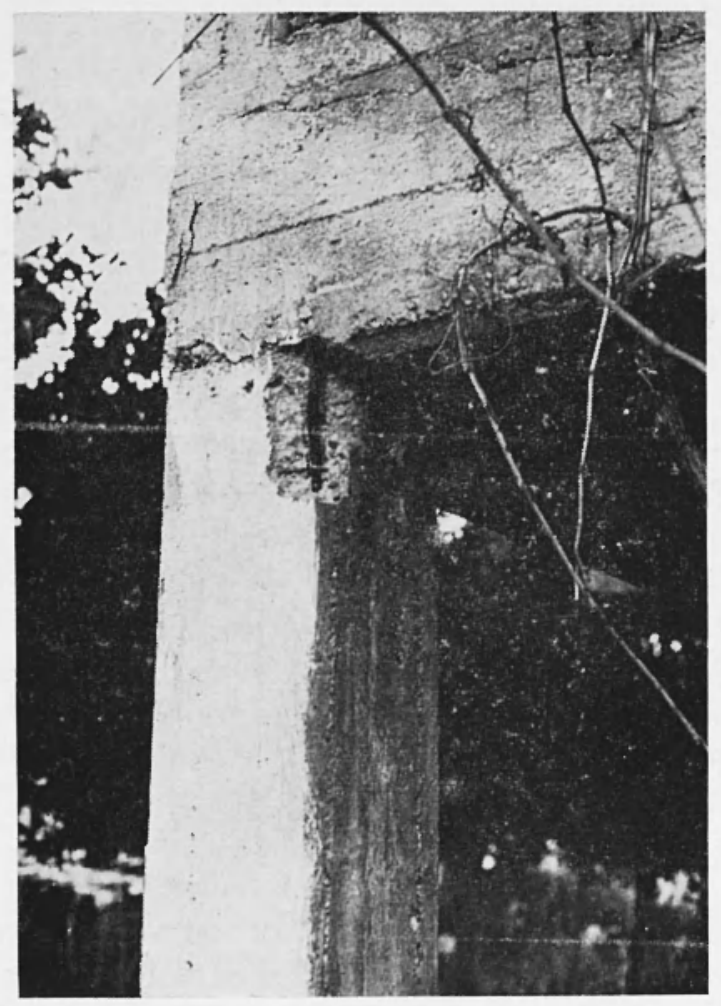

(a)

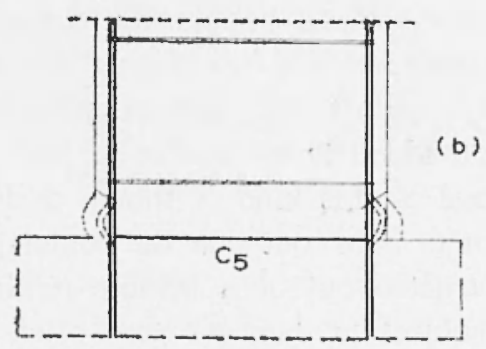

Fig. 28. Bending of reinforcing bars at the top and botton of concrete columns in the epicentral region, for $C_{5}$ see Fig. 31. 


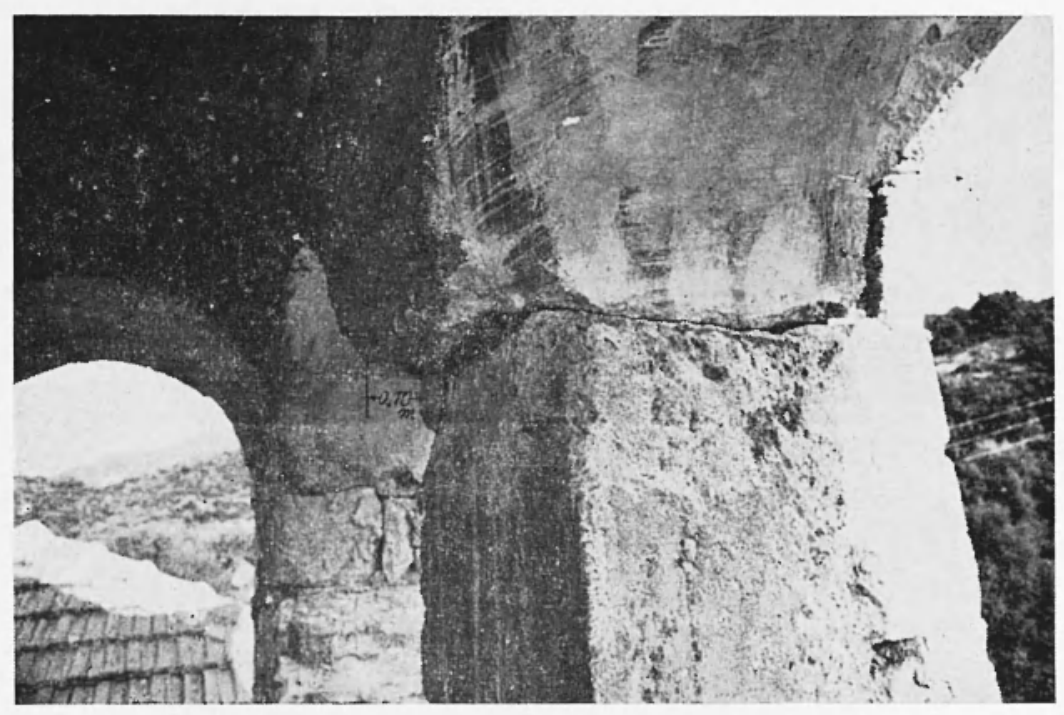

Fig. 29. Construction joint with no connection of the two adjacent parts, caused a dislocation of the top part of the church steeple at Kaloudi.

\subsection{DiRECTION OF MOVEMENT.}

The direction in which various subjects fall was also recorded. Almost all these subjects were restrained to one direction of the possibility of movement more than to the other direction during their motion due to the earthquake. The directions of overall movements are schematically plotted as a non-polar azimuth in Fig. 30. A pronounced coincidence of the directions of these movements was found to be parallel to $N-E, S-W$. These directions are perpendicular to the main axes of the seismoscope records, at Messologhi. 


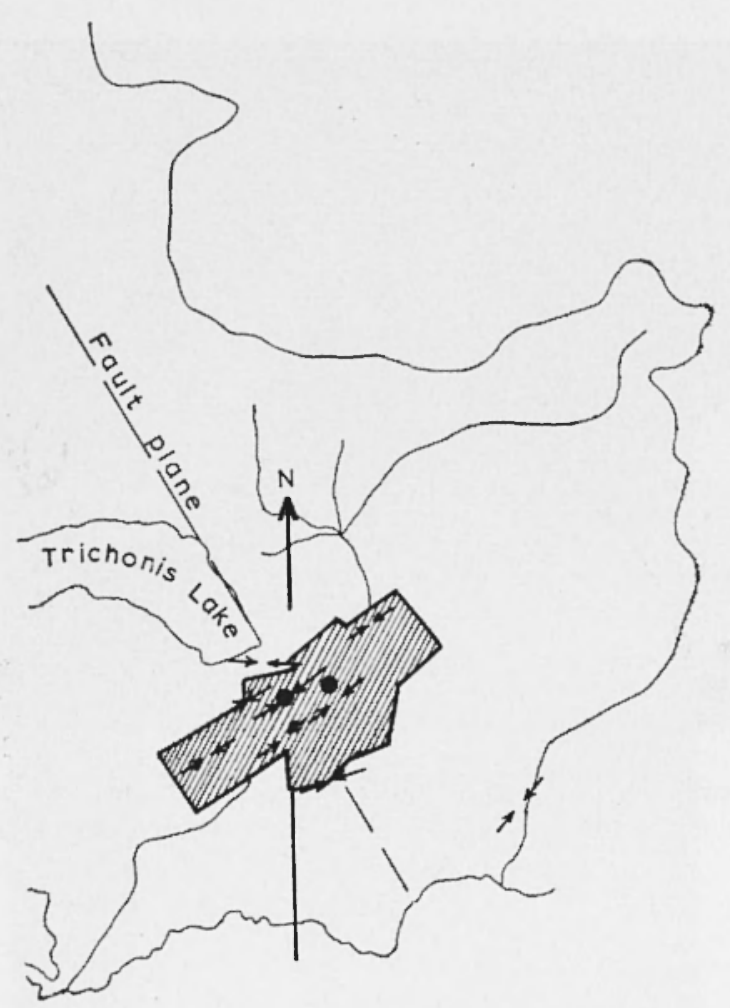

Fig. 30. Rose diagram of fall directions.

\subsection{Damages to bulldings AND BRIDGes.}

In the following a selected series of damaged buildings will be presented in order mainly to show the progress of the damages after the first and the two other main earthquakes, which has been also partly presented above.

In Figs 31 and 32 a comparison of the damages due to the first and third earthquake may be carried out for an old two story stonework and for a one and a half story contemporary houses respectively.

Almost all of the churches in the meizoseismic region behaved during the present earthquakes very badly. This may be attributed to 


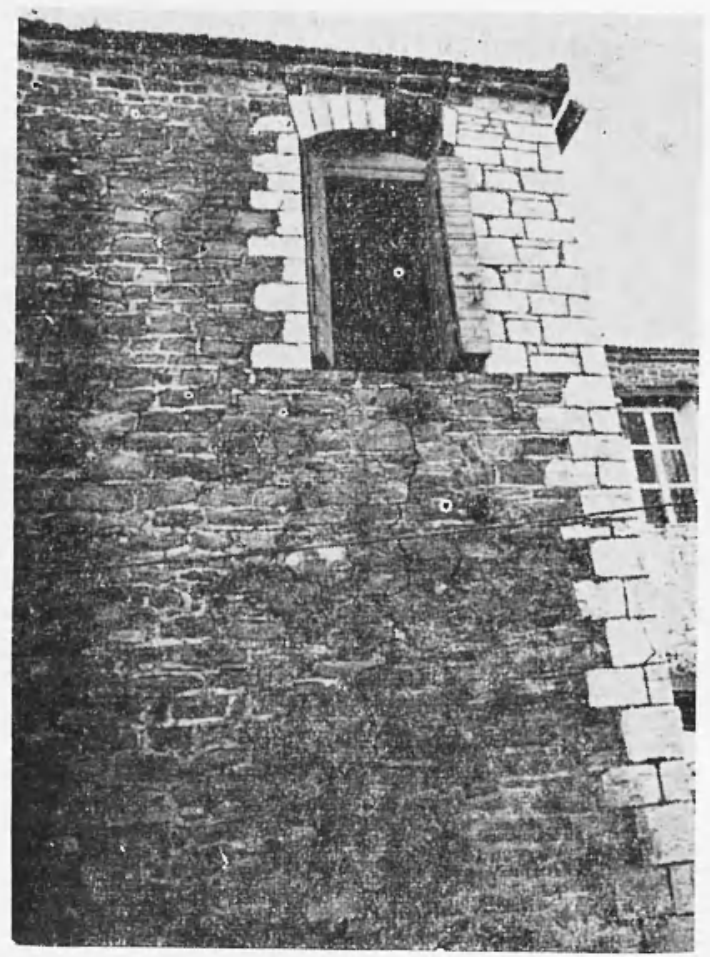

(a)

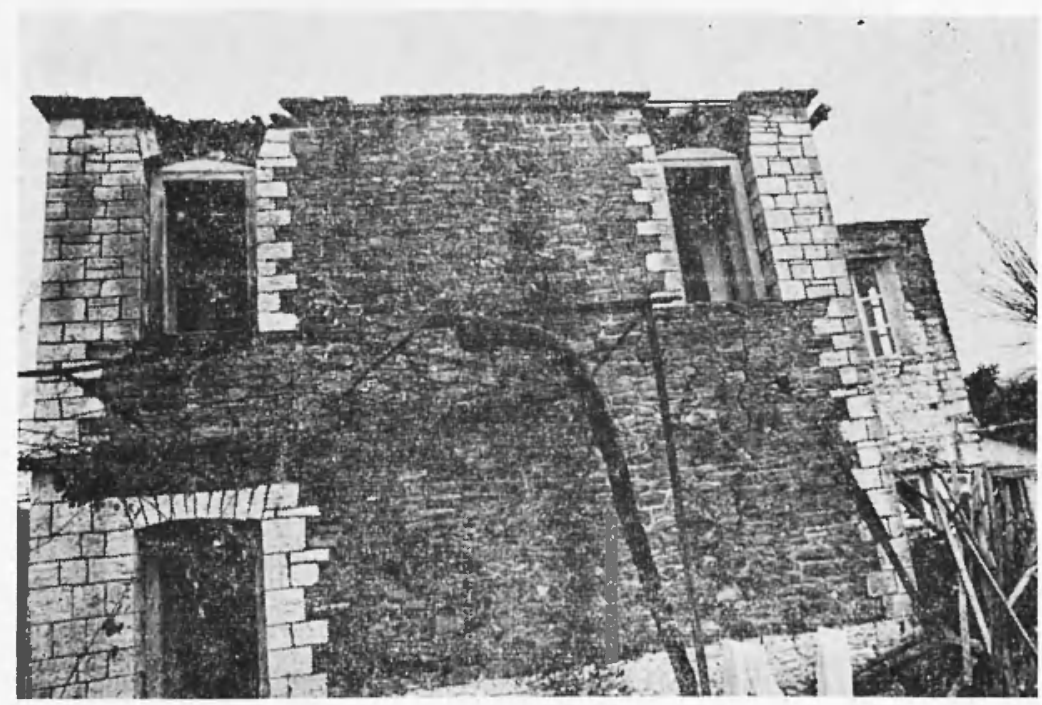

(b)

Fig. 31. Progress of damage to a two story old house out of stonework. After the first earthquake only that part of the building shown in $(a)$ was damaged. $(b)$ is after the third earthquake. 

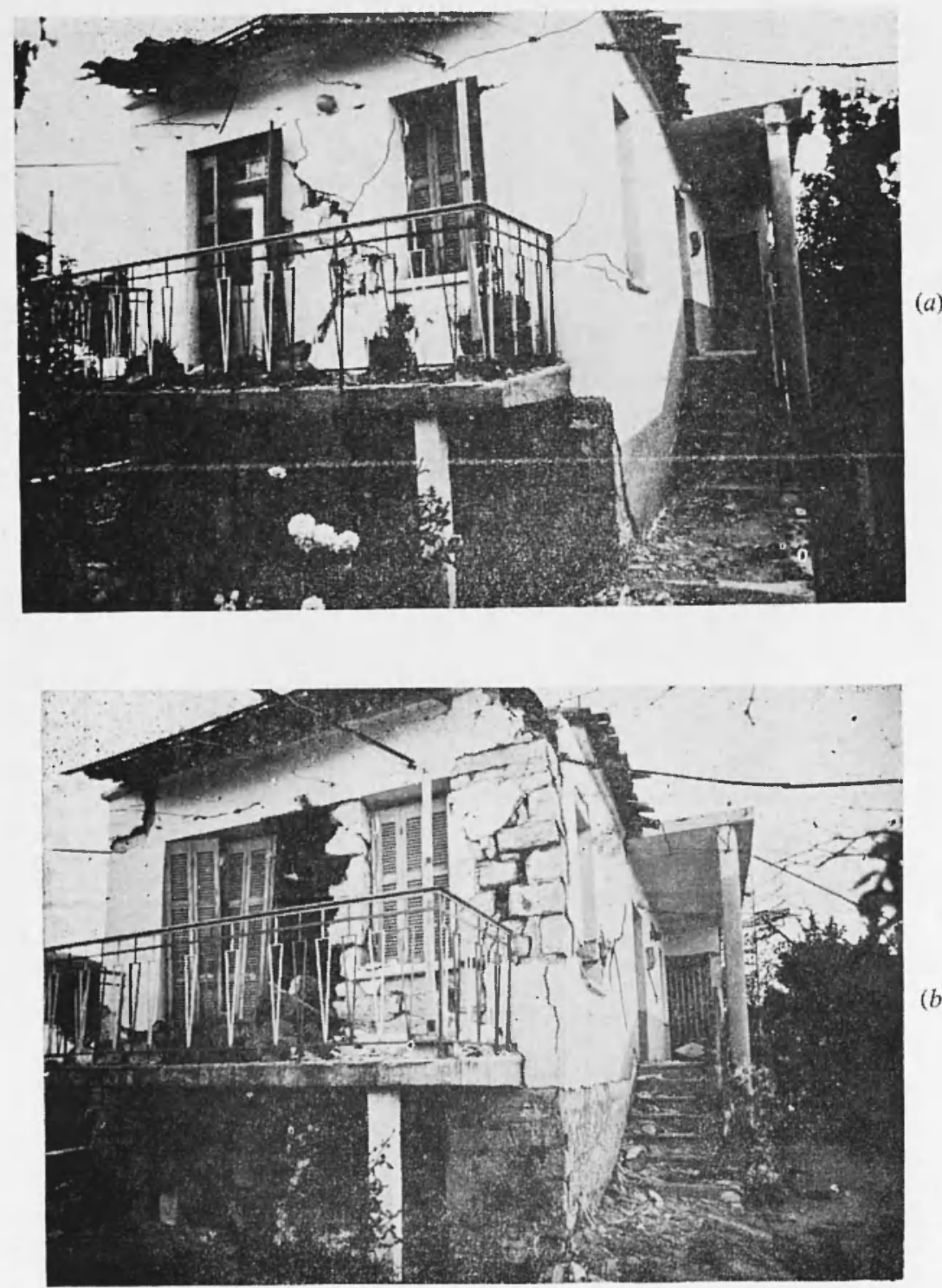

(b)

Fig. 32. Destruction of a contemporary one and a half story building after the third $(b)$ earthquake, while it was not repaired after the first one $(a)$. The destruction of the front parts of the wall is proportional to their rigidity. 
the fact that the domes out of brick and stoneworks can not at all be considered as earthquake resistant. This kind of structures showed inadequate horizontal reinforcing above the level of lintels, in view of the heavy masses concentrated at the top of the structures. An other reason of damages may be attributed to the strong vertical component of the ground motion which results, due to the function of the dome, to the development of two symmetrical horizontal forces, acting cutwards to the dome.

A last case is the effect of adjoining structures to the main building of church as these sometimes, are the steeples. In Fig. 33 the mechanism of the relevant function is outlined. The same mechanism yields also for the chimneys of low houses. In Fig. 34 an example of this kind of destruction is shown.

In Fig. 35 a typical constructional error is presented. This kind of construction yields for almost all houses which are constructed on the downstream part of the raod where also is the entrance of the house. In Fig. $5 b$ a simple separation space is proposed between the two structures.

Damages of the protective works at the level of pavement of the small stonework bridge from Douneika to Kato-Makrynou village were observed. The piers and foundations were unaffected. The rest bridges out of stonework, reinforced, or not, concrete and the steel bridge at Chani Bania behaved quite well. The superstructures were only partially damaged.

The various retaining walls suffered considerable damages in genera!. The most of those constructed without any mortar almost collapsed, while some of those constructed with mortar cracked or were dislocated and rotated around a vertical axis. Those out of reinforced concrete behaved almost quite well.
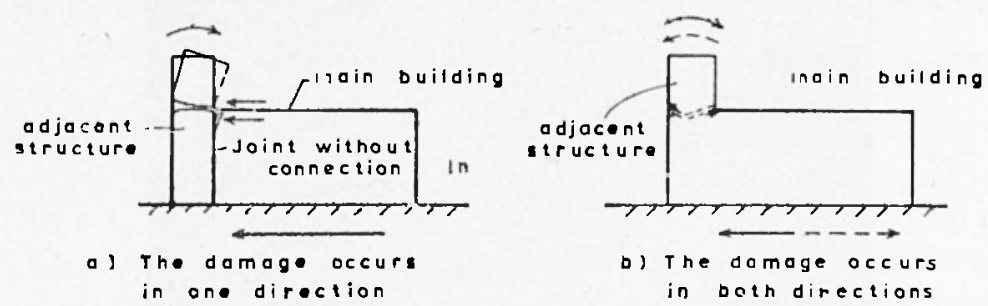

Fig. 35. Mechanism for the presentation of damages of adjacent structures to main body of buildings. 


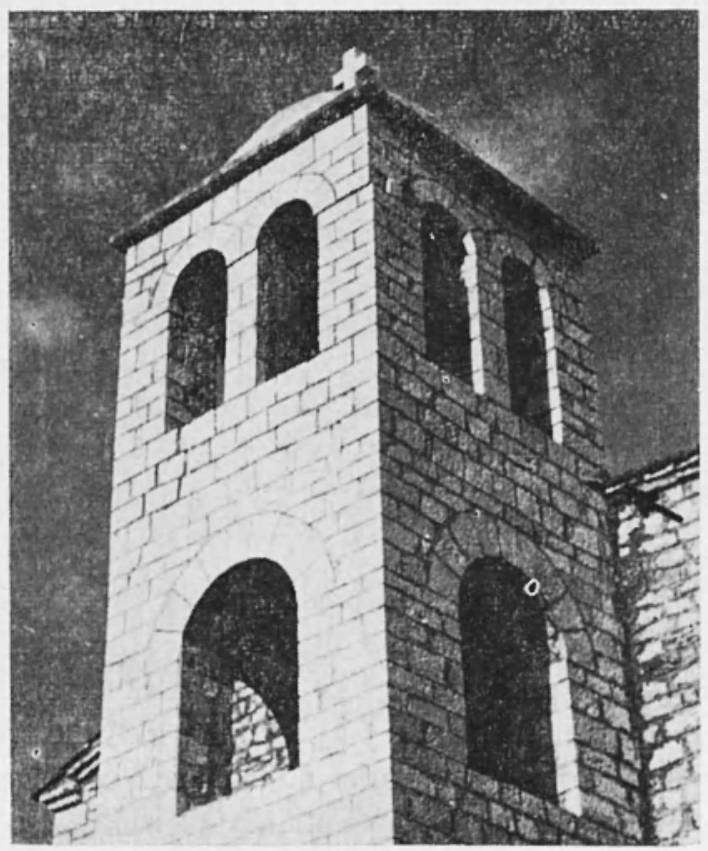

(a)

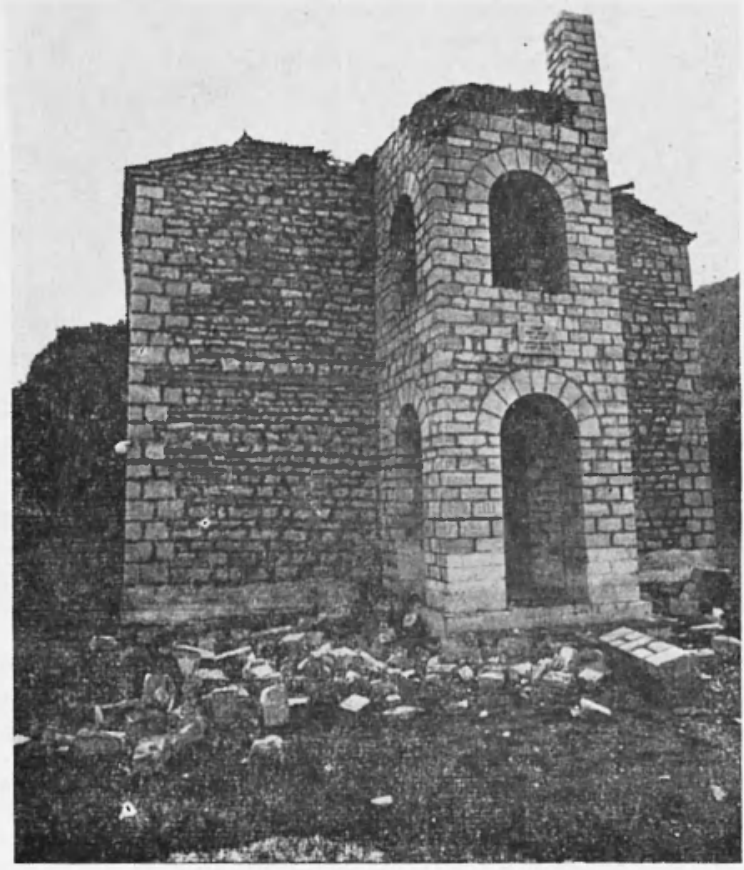

(b)

Fig. 34. The steeple was struck by the main body of the church at Kaloudi, giving also a rotation to its top part, after the first earthquake (a). The third earthquake caused the overturning of the lop part of the steeple, which fall into the church (b). 


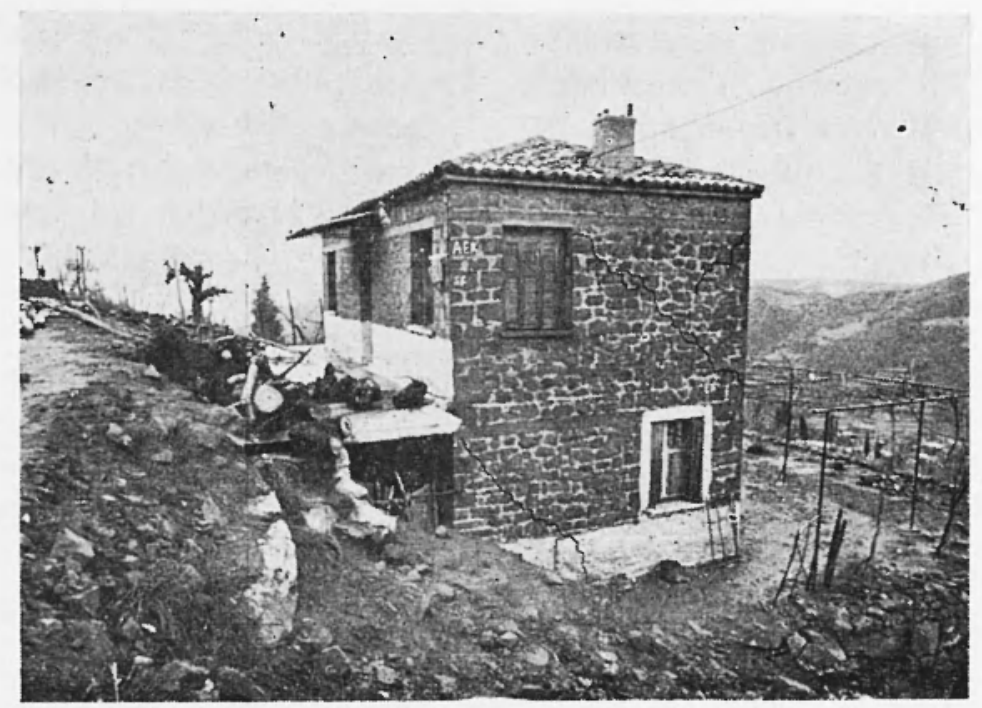

(a)

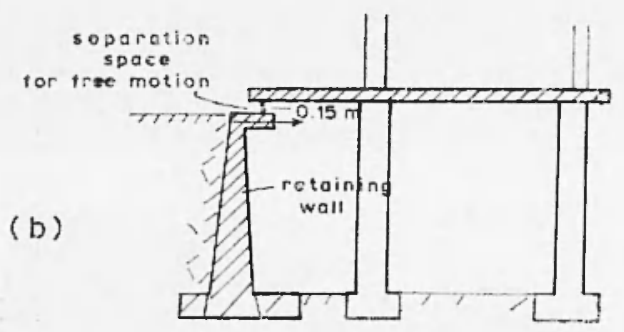

Fig. 35. (a) A typical constructional error. The top of the retaining wall is connected with the reinforced concrete slab of the roof of the ground floor. The retaining wall functions after the creation of considerable horizontal displacements, which the structure may not be able to follow elasticity. (b) A possible preventive measure hy separating the two structures.

\section{DAMAgE TO GROUND.}

As a result of the earthquake activity was the generation of some landslides, settlements or cracks on the ground or dikes, and on some pavements of the roads laying on earthbanks. It was also reported falling of stones from escarpments.

A limited landslide is observed at the south of the village Analepsis.

A ground cracking was observed along the pavement of the road 
from Vlachomandra to Douneika and at various points of the road.

The most interesting ground cracking was observed at the Cophtra Valley after the December 31, 1975 earthquake. The ground surface is horizontal, and the cracking had a total length of about $200 \mathrm{~m}$ directed $N 125^{\circ} \mathrm{E}$, as is shown in Fig 36. No one offset is observed. This fracture
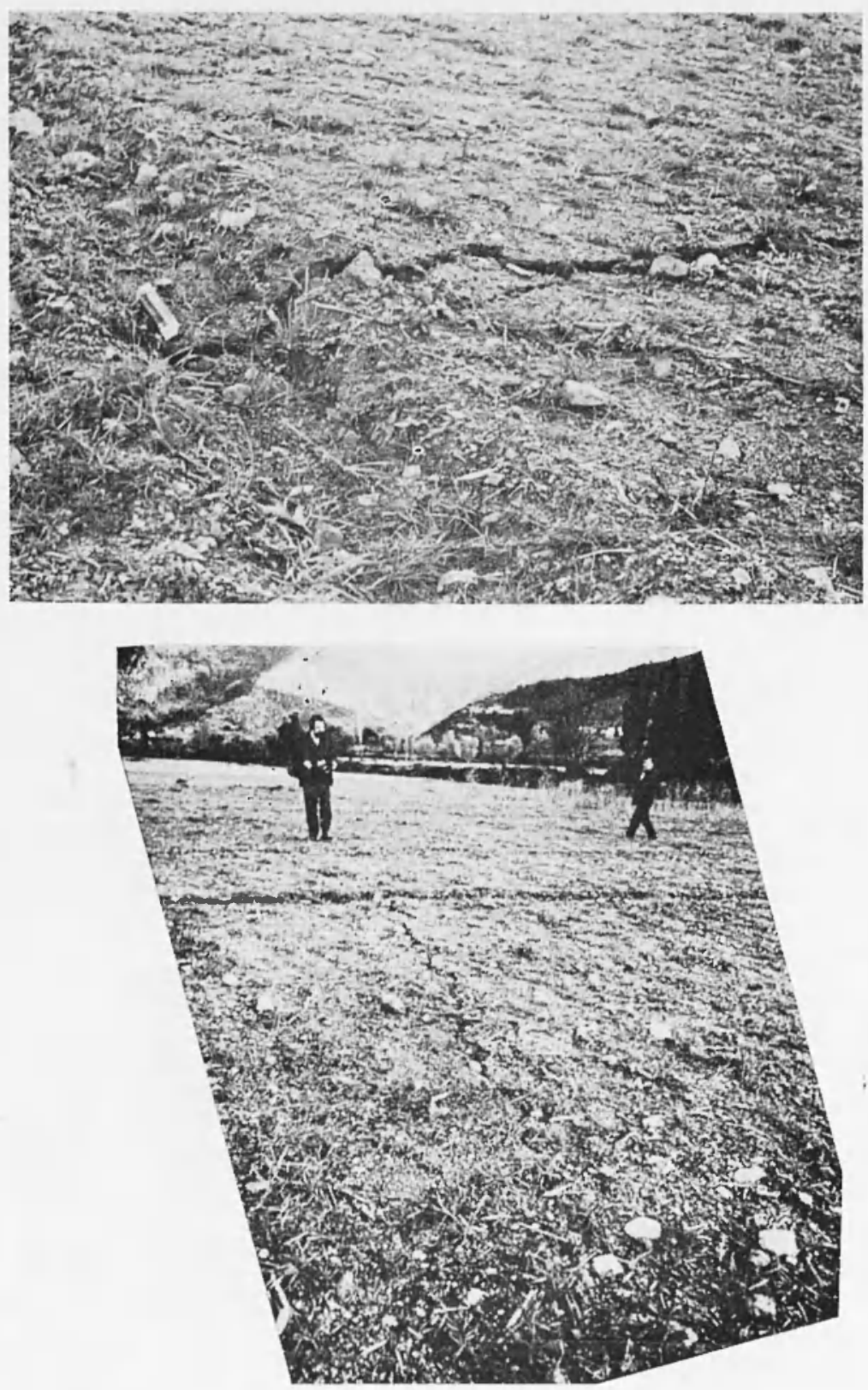

Fig. 36. Fissures vertical to the Cophtra Valley after the December 31, 1975 carthquake. 
may be a surface expression of the fault N. 3, Fig. $19 \mathrm{~b}$ which, as discussed in paragraph 9, has the same direction.

\section{Conclusions.}

The present study brings out the following results:

1) The frequency of occurrence of the aftershock sequences decays uniformly in time over an interval of more than 15 days according to an inverse power law.

2) The magnitudes of aftershocks are distributed according to the Gutenberg-Richter magnitude-frequency reiationship with $b$ value equal to 1.00 . The $b$-value of the sequences is stationary in time but depends ufon the focal depth.

3) The areal distribution of the aftershock epicenters is almost circular, and the majority of them lie on faults with surface manifestation.

4) The compressional and shear phases were observed in the investigation of the deformation characteristics of all sequences. Moreover, a third phase was observed in the last sequence whose energy was released by the major late aftershock.

5) The relaxation time of the shear phase for the first and third cases was found equal to 0.3 and 0.7 days respectively.

6) The seismic activity is produced by the action of compressional stresses on the Cophtra anticline associated with a slight downwards movement of its upper part.

7) The damages of buildings are concentrated on rather old hcuses. In some of them, problems of foundation were observed.

8) Almost all church buildings showed a rather bad performance during the present series of earthquakes, although materials of gcod quality were used and good construction of the walls was made. This can be attributed to the construction of walls having long dimensions without any or enough connection to each other. The horizontal connection at the level of the roof support was inadequate or 
very poor. In this case circumferential connective beams out of reinforced concrete should be used.

9) Many cases of damages were reported, caused by collision of adjcining buildings due to the negligible width of the vertical joints, and the different dynamic behaviour of even similar buildings.

10) It was observed that in the case of additions, repairs, or strengthenings of existing buildings, damages were observed at the points of connection. This is attributed to the different dynamic behaviour between the two constructions, to the behaviour of materials themeselves, as well as to the weak connection of the two constructions. The same was observed along the construction joints of the same structure, in the case of reinforced concrete structures.

11) Interesting observations are made for one to two story "flexible " structures having a load carrying system out of reinforced concrete. Some of the damages of this category have been described previously, and it may be concluded that the seismic behaviour of this type of structures is very sensitive to the effect of factors which are considered until now as of minor importance. The opposite yields for the "rigid" structures which have symmetrical reinforced concrete shear walls at both directions.

12) A clcse relation between damages and soil conditions was also observed that yields for the epicentral regions. Small damages, say degree $\mathrm{V}$ for buildings founded on bed rock, heavy damages, say degree VII for buildings founded on soft soils underlayed by an outcroping bed rock, intermediate damages, say degree VI on soft soils of small to medium depth and almost no damages, say degree IV on deep soft soils.

ACKNOWLEDGEMENTS.

The authors are grateful to Professor A. Galanopoulos, University of Athens for his encouraging attitude and for his critical reading of the manuscript of this paper; and to Associate Professor J. Drakopoulos, University of Athens, for his much helpful discussions and remarks on the paper. 
The authors want to thank Dr. J. Bornovas, Director of the Institute of Geological and Subsurface Research, Athens, for his courtesy in discussing the geologic and tectonic setting of the paper.

The authors express their sincere appreciation to Assistant Mr. G. Leventakis, University of Athens, for his attendance to the field trips, and his help for the installation of the portable seismographs.

\section{REFERENCES}

(1) Barounis A. N., 1975. - Seismology of man made earthquakes. "Mining Metallurgical Chronicles». 23.

(2) ВӒтH M., DUDA S. J., 1964. - Earthquake volume, fault plane area, seismic energy, strain deformation and related quantities. "Annali di Geofisica », 17, pp. 35j-j68.

(3) BERG E., 1968. - Relation between earthquake foreshocks stress and main shocks. "Nature », 219, pp. 1141-114j.

(4) BLume J. A., 1965. - Earthquake ground motion and engineering procedures for important installations near active faults. "Proceedings 3 rd WCEE », New Zealand, 3, 1V-53.

(5) Bonilla M. G., 1970. - Surface faulting and related effects. "Earthquake Engineering, R. Wiegel coordin. editor », Chapt. 3, pp. 47-74.

${ }^{(6)}$ Galanopoulos A., Bornovas I., Delibasis N., 1971. - Seismotectonic map of Greece. "Seism. Institute Nat. Obs. Athens and Inst. Geol. Subsurface Res.", Athens.

(7) Bornovas 1., 1974. - Note on the Seismotectonics of Greece. « Proceedings of the seminar on the seismotectonic map of the Balkan Region ", Dubrovnik 197j, UNESCO, Skopje.

$\left(^{8}\right)$ B. P. Co., Ltd., 1971. - The Geological results of petroleum exploration in Western Greece. "Inst. Geol. and Subsurface Research", 10, Athens.

(') Comninakis P. E. et al., 1968. - Foreshock and aftershock sequences of the Kremasta earthquake and their relation to the artificial lake. "Annali di Geofisica », 21, pp. 39-71.

(10) Comninakis P. E., 1975. - A contribution to the investigation of the seismicity of the Area of Greece. "Dissertion, Univ. of Athens".

(II) Donovan N. C., 1973. - A statistical evaluation of sirong motion data including the Feb. 9, 1971. San Fernando Earthquake. "Proceedings 4 th WCEE », paper N. 155, Rome, Italy.

(12) Drakopoulos I., 1968. - Characteristic parameters of fore - and altershock sequences in the region of Greece. "Dissertation, Univ. of Athens". 
(13) Drakopoulos J., Srivastava H. N., 1970. - Investigations of the aftershocks of July 4, 1968. "Annali di Geofisica ", 23, pp. 1-20.

(14) Drakopoulos J., 1974. - Conditions and triggering mechanism of seismic activity in the regions of Kremasta-Kastraki dams. "Docent Thesis Univ. of Athens ", pp. 1-126.

(15) Eaton, J. P., 1969. - Hypolayr, a computer-program for determing hypocenters of local earihquakes in an earth consisting of unilorm flat layers over a hall space. "U.S. Geological Survey, open file report».

(16) Galanopoulos A., 1965. - The large conjugate lault system and the associated earthquake activity in Greece. "Ann. Geolog. Pays Hellen. », 18, 119-134.

(17) Galanopoulos A., 1965. - Evidence for the seat of the sirain production forces. "Annali di Geofisica », 18, pp. 399-409.

(18) Galanopoulos A., 1967. - The influence of the fluctuation of Marathon Lake elevation on local earthquake activity in the Attica Basin. "Annales Geolog. Pays Hellen. », 18, pp. 281-306.

(19) Galanopoulos A., 1968. - On quantitative determination of earthquake risk. "Annali di Geofisica », 21, N. 2.

(20) Galanopoulos A. G., 1971. - Fundamentals of seismology and of the physics of the Earth's interior. Athens.

(21) GuPTA H. K. et al, 1972. - Some discriminatory characteristics of earthquakes near the Kariba, Kremasta, and Koyna arificial lakes. «Bull. Seism. Soc. Am. », 62, 493-507.

(22) Gutenderg B., Richter C. R., 1956. - Earthquake Magnitude, Intensity, Energy and Acceleration (second paper). "BSSA », 46. N. 2., pp. 105-145.

(23) HouSNER G. W., 1969. - Engineering estimates of ground shaking and maximum earihquake magnitude. "Proceedings 4 th WCEE ", Santiago, Chile, 1, A-1.

(24) IsACKS B., Oliver J., 1964. - Seismic waves with frequencies from 1 to 100 cycles per second recorded in a deep mine in Northern New Jersey. "BSSA », 54, pp. 1941-1979.

(25) KarnIK V., 1969. - Seismicity of the European area. Part I. "D. Reiden publishing Co. », Dordrecht - Holland.

(26) KNOPOFF L., 1964. - The statistics of earihquakes in southern California. «BSSA », 54, pp. 1871-1873.

(27) Kokinopoulos F. E., TAsios T., 1966. - The earthquake of Peloponnesus, April 1965 - A survey of the created damages. "Proceedings of third symposium on earthquake engineering, Roorkie ", India.

(28) Leontaris S. N., 1968. - Geomorphological investigations of Aeloloakarnania Basin. "Dissertation, Annal. Geol. Pays Hellen. », 19, pp. 541-620.

${ }^{(29)}$ MAKRIS J., 1976. - The crust and upper mantle of the aegean region obtained from deep seismic soundings. 
(30) Mogr K., 1963. - Some discussions on aftershocks, foreshocks and earthquake swarms. - The fracture of a semiinfinite body caused by an inner stress origin and its relation to the earthquake phenomena. "Bull. Earth. Res. Inst. Tokyo Univ. ", 41, pp. 615-658.

(31) Minakamı T., 1960. - Fundamental research for predicting volcanic eruptions, 1. Earthquakes and crustal deformations originating from volcanic activities. "Bull. Earth. Res. Inst. Tokyo Univ.", 38, pp. 497-544.

(32) PAGE R. A., Boore D. M., Joyner W. B., Coulter H. W., 1972. - Ground motion values for use in the seismic design of the Trans-Alaska pipeline system. «U. S. Geological Survey», Circular N. 672.

(33) PAPAZACHos B.. et al, 1967. - A/tershock sequences of some large earthquakes in the Region of Greece. "Annali di Geofisica », 20, N. 1.

(34) Papazachos B. C., 1974. - On the relation between certain artificial lakes and the associated seismic sequences. "Engineering Geology», 8, 39-48.

(35) Ritsema A. R., 1974. - The earthquake mechanisms of the Balkan Region. "UNDP Project REM/70/172», De Bilt.

(36) Shebalin N. V., 1972. - Macroseismic dala as information on source parameters of large earthquakes. "Phys. Earth Planet. Interiors », 6.

(77) Seed H. B., Idriss 1. M., Dezfulian H., 1970. - Relationships between soil conditions and building damage in the Caracas earthquake of July 29, 1967. «N. EERC 70-2 ».

(38) Seed H. B., Murarka R., Lysmer J., Idriss I. M., 1975. - Relationships between maximum acceleration, maximum velocity, distance from source and local site conditions for moderately strong earthquakes. "N. EERC 75-17».

(39) Sponheuer W., 1960. - Methoden zur herdtiefenbestimmung in der makroseismik. "Freib. Forschungshefte", C 88 . Berlin.

(10) Snow D. T., 1972. - Geodynamics of seismic reservoir. Proc. Symp. on percolation through fissured rocks. "Deutsche Gesellschaft für Erd-und Grundbau ". Stuttgart, T 2-J, pp. 1-19.

('I) Sobolera O. V. and SCHKLJAR P. G., 1976. - The change of earthquakes mechanism during the reservoir impounding.

(2) Trifunac M. D. and Brady A. G., 1976. - Correlations of peak acceleration. velocity and displacement with earthquake magnitude, distance and site conditions. "Earthquake Engineering and Structural Dynamics", 4, N. 5, pp. 455-471. 